\title{
An argument for sub-tonal features: Floating tones in two Otomanguean languages*
}

\author{
Eva Zimmermann \\ University of Leipzig \\ eva.zimmermann@uni-leipzig.de
}

\begin{abstract}
Assuming that tones are not phonological primitives but have a complex internal featural structure predicts that the same surface tone can have different phonological representations in one language. I argue in this paper that this assumption of sub-tonal features allows a straightforward analysis for different patterns of apparently exceptional or asymmetric behaviour of floating tones. This paper hence argues for the importance of (abstract) underlying representations that allow purely phonological accounts of apparent lexical idiosyncrasies. In addition, it adds to the growing body of evidence for sub-tonal features.
\end{abstract}

Keywords: tones; sub-tonal features; Otomanguean languages; underlying representation

\section{Introduction}

Assuming that tones are not phonological primitives but have a complex internal featural structure predicts that the same surface tone can have different phonological representations in one language. I argue in this paper that this assumption of sub-tonal features allows a straightforward analysis for different patterns of apparently exceptional or asymmetric behaviour of floating tones and hence for the importance of (abstract) underlying representations that allow purely phonological accounts of lexical idiosyncrasies. In addition, the case studies in this paper add to the growing body of evidence for sub-tonal features.

This paper presents two case studies of exceptional tonal behaviour in different Otomanguean languages that explore the predictions arising from assuming sub-tonal features. In both languages, several morphemes

\footnotetext{
For valuable comments and discussion I am grateful to the audiences at OCP 13 in Budapest and CLS 52 in Chicago. I am especially indebted to Jereon Breteler and Jochen Trommer for their constructive comments. This research was supported by a DFG grant to the project 'Featural Affixes: The Morphology of Phonological Features' (TR 521/6-1).
} 
contain so-called floating tones that associate to an adjacent morpheme and hence influence or overwrite the tonal melody of a base. This standard autosegmental account of floating tones is challenged by two types of asymmetries found in the two languages. In San Esteban Atatláhuca (=MIB; Mak 1953; McKendry 2013) ${ }^{1}$ floating tones show different instances of type allomorphy and hence trigger different types of changes for different bases. In $(1 \mathrm{a}+\mathrm{b})$, a floating low tone $(=4)^{2}$ results in a stepwise lowering to a tone one level lower. Such a stepwise process is in itself already challenging for an account where the four level tones of the language are represented as tonal primitives in the phonology. In addition, it can be seen that the lowering effect is not consistent for bases starting with the highest tone 1: A tone 2 results in (1a) but a tone 3 in (1c). In Macuiltianguis Zapotec (= MacZ; Broadwell et al. 2011), on the other hand, different floating tones show a position asymmetry where one floating tone 1 is consistently realized on the first TBU (2a) and another floating tone 1 (= part of another morpheme) can be realized on either the first or the second TBU (2b). In addition, these two different floating tones trigger different effects for long tones that show a contour tone after one floating tone (2c) but become consistently high after the other $(2 \mathrm{~d})$.

(1) Floating low tone in MIB

$$
\begin{array}{cc|c}
\text { a. } & \text { fl. tone } 4+1.4 & \mathbf{2 . 4} \\
\text { b. } & \text { fl. tone } 4+2.4 & \mathbf{3 . 4} \\
\hline \text { c. } & \text { fl. tone } 4+1.1 & \mathbf{3 . 1}
\end{array}
$$

(2) Floating high tones in MacZ

\begin{tabular}{cc|l} 
a. & fl. tone $1_{\mathrm{B}}+2.3$ & $\mathbf{1 . 3}$ \\
b. & fl. tone $1_{\mathrm{A}}+2.3$ & $2 . \mathbf{1}$ \\
\hline c. & fl. tone $1_{\mathrm{B}}+33.1$ & $\mathbf{1} 3.1$ \\
d. & fl. tone $1_{\mathrm{A}}+33.1$ & $\mathbf{1 1} ! 1$
\end{tabular}

I argue that both these asymmetries follow in an account based on subtonal features: The different effects of floating low tones in MIB follow from assuming a complex floating tonal structure consisting of two floating low tone feature on different tiers of the tone representation: both result in lowering but to different degrees. The position asymmetries between different morphological high tones in MacZ, on the other hand, follows from assuming that these high tones have different underlying representations: a fully specified tone-feature complex needs to be realized on the adjacent

${ }^{1}$ As is common in literature on Mixtec varieties (e.g., McKendry 2013), I use the ISO 639-3 code as an abbreviation for the language.

${ }^{2}$ I follow the notational tradition of Central Americanists to use 1 for the highest tone and 3 or 4 for the lowest tone in a three- and four-tone system respectively. Importantly, the tone-number correspondences are hence the reverse of the Chao numbers (Chao 1930) often used in the Asian tradition. 
TBU whereas an underspecified tone feature is more mobile and can be realized on non-adjacent positions. I will show how all apparent exceptions in the tonal behaviour of MIB and MacZ fall out from standard phonological constraints if the floating tones of the languages have a (complex) sub-tonal structure.

This paper is structured as follows: in section 2 , I present the theoretical background assumptions and most notably the assumption of sub-tonal features. In sections 3 and 4, I turn to the two case studies of MIB and MacZ respectively. In both sections, the data and the challenge this pattern poses for the assumption of tonal primitives is discussed before the analysis based on sub-tonal features is presented. I conclude in section 5 .

\section{Theoretical background}

\subsection{Tonal features}

The most crucial background assumption for the following analyses is the assumption of tonal features. Tones are taken to be phonologically complex structures of register and tone features (Yip 1980; Pulleyblank 1986; Snider 1999; Bao 1999) in a dominance relation (Yip 1989; Snider 1990; Hyman 1992). The combination of these two (sub-)tonal features then results in four possible tone specifications given in $(3)$. $[ \pm \mathrm{U}]$ abbreviates the register feature $[ \pm$ Upper $]$ and $[ \pm \mathrm{r}]$ the tone feature $[ \pm$ raised $] .^{3}$

(3) Tonal features

\begin{tabular}{|c|c|c|c|}
\hline Extra high & High & Mid & Low \\
\hline$+\mathrm{r}$ & $-\mathrm{r}$ & $+\mathrm{r}$ & $-\mathrm{r}$ \\
$\mid$ & $\mid$ & $\mid$ & $\mid$ \\
$+\mathrm{U}$ & $+\mathrm{U}$ & $-\mathrm{U}$ & $-\mathrm{U}$ \\
\hline
\end{tabular}

Various arguments have been made for such a representation of tones. For one, such a sub-tonal structure predicts processes between non-contiguous tones (Odden 1995), register shifts (Snider 1990), partial lowering/raising of tones (Hyman 2013), or stepwise tonal shifts (McPherson 2017). On the other hand, the assumption of tonal features predicts that tones with the same surface interpretation might have different underlying representations and hence behave differently in the phonology (Snider 1998; Picanço

${ }^{3}$ Following the terminology in Pulleyblank (1986) or Yip (1989). Different names exist as, for example $[ \pm$ high] instead of $[ \pm$ raised], in, for example, Yip (1980). 
2005). The case study on MIB in section 3 strengthens the former class of arguments in showing apparently non-systematic changes triggered by a single floating tone and the case study on MacZ in section 4 strengthens the latter argument in showing two floating H-tones with different phonological behaviour in a single language.

The tonal representations of the four tone system in MIB and the three level tone system of MacZ that are crucial in the analyses in 3.2 and 4.2 are given in (4) and (5). Cross-classifying the two tonal features straightforwardly predicts the four-tone system of MIB (4). A crucial additional assumption is the existence of underspecified register tones: $\mathrm{A}[ \pm \mathrm{U}]$ feature can lack a $[ \pm \mathrm{r}]$ specification. In MIB, those underspecified tones are taken to be phonetically interpreted with a default $[+\mathrm{r}]$ value. An underspecified $[+\mathrm{U}]$ is hence phonetically a tone 1 and an underspecified $[-\mathrm{U}]$ equals a phonetic tone 3 .

MacZ, on the other hand, has only three level tones and there are hence two possibilities to specify a mid tone. In MacZ, there are good arguments to assume that the mid tone is $[+\mathrm{U},-\mathrm{r}]$ (and not $[-\mathrm{U},+\mathrm{r}]$ ). Under this assumption, it forms a natural class with high tones; a prediction that is borne out since high $(=1)$ and mid $(=2)$ tones undergo phonological spreading in MacZ. As in MIB, underspecified register tones exist that are taken to be interpreted with a default $[-r]$ value in MacZ: An underspecified $[+\mathrm{U}]$ is hence phonetically a mid tone and a $[-\mathrm{U}]$ equals a phonetic low tone.

(4) The tones of MIB

\begin{tabular}{|c|c|c|c|c|c|}
\hline 4 & 3 & 2 & 1 & 3 & 1 \\
\hline$-r$ & $+\mathrm{r}$ & $-r$ & $+\mathrm{r}$ & & \\
\hline$-\mathrm{U}$ & $-\mathrm{U}$ & $+\mathrm{U}$ & $+\mathrm{U}$ & $-\mathrm{U}$ & $+\mathrm{U}$ \\
\hline
\end{tabular}

(5) The tones of MacZ

\begin{tabular}{|c|c|c|c|c|}
\hline 3 & 2 & 1 & 3 & 2 \\
\hline$-r$ & $-\mathrm{r}$ & $+\mathrm{r}$ & & \\
\hline$-\mathrm{U}$ & $+\mathrm{U}$ & $+\mathrm{U}$ & $-\mathrm{U}$ & $+\mathrm{U}$ \\
\hline
\end{tabular}

Note that the terms ' $1 / 2 / 3 / 4$-tones' in the following discussion always refer to this phonetic interpretation of a phonological structure containing $[ \pm \mathrm{U}]$ and potentially $[ \pm \mathrm{r}]$. 


\subsection{Coloured Containment}

The theoretical background for the following OT-analysis is Coloured Containment (van Oostendorp 2006; Trommer 2011; Trommer \& Zimmermann 2014; Zimmermann 2017), a version of containment-based OT (Prince \& Smolensky 2004). In such a theory, no phonological element may be removed from the structure (6), elements may only remain phonetically uninterpreted if they are not properly integrated into the prosodic structure (McCarthy 1979; Steriade 1982; Itô 1988). ${ }^{4}$

\section{(6) Containment (Prince \& Smolensky 2004)}

Every element of the phonological input representation is contained in the output.

Containment as assumed here also assumes that association lines can not be deleted, only marked as phonetically invisible for the phonetics (Goldrick 2000; van Oostendorp 2006; Revithiadou 2007; Trommer \& Zimmermann 2014). A phonetically visible phonological element is hence one that is properly integrated under the highest prosodic node via a path of phonetically visible association lines. A second assumption inside Coloured Containment are morphological 'colours' or affiliations: Every morpheme is taken to have an underlying colour and all phonological elements that are part of the underlying representation of this morpheme bear this colour that can not be changed. This assumption hence allows to differentiate between underlying (= coloured) and inserted (= colour-less) elements and between elements of the same or a different morphological colour (van Oostendorp 2006; 2007; 2008; Revithiadou 2007). Given that the phonology can distinguish between underlying and epenthetic and phonetically realized and unrealized elements, at least the three different types of association lines in (7) exist in Coloured Containment. There is no agreement whether the fourth possible type of association line (= epenthetic but phonetically invisible) exists or is excluded by GEN (for different positions cf., for example, Trommer 2015 and Zimmermann 2017). The present analysis is perfectly compatible with both assumptions ${ }^{5}$ and will assume the more restrictive inventory in (7) for ease of exposition.

${ }^{4}$ This is a simplification in the domain of tone. Tones that are not associated to a TBU in a phonetically visible way can of course very well have a phonetic effect given that an unassociated low tone between two high tones is one standard representation for downstep (Pulleyblank 1986; Odden 1988).

${ }^{5}$ Under the enriched inventory of four possible types of association lines, the parsing constraints 9 would simply exist in different versions; one demanding a link of any type and a more specific version demanding an association that is either underlying 
(7) Types of association lines

\begin{tabular}{|c|c|c|}
\hline \multicolumn{2}{|c|}{ Underlying } & Epenthetic \\
Visible & Invisible & Visible \\
\hline \multirow{1}{*}{$\neq$} & $\neq$ & $\vdots$ \\
\hline
\end{tabular}

The structures in (8) illustrate the notations and mechanisms of phonetic (in)visibility in containment. The high tone in (8a) remains phonetically uninterpreted since it is not associated to a TBU and therefore not integrated into the structure at all. And the low tone in (8b) remains phonetically uninterpreted since it is only linked to a TBU via phonetically invisible association lines. Conversely, all association lines linking phonetically invisible elements are taken to be phonetically invisible as well (Zimmermann 2017). Phonetically unrealized elements are marked with a grey background in the following to ease readability.

(8) Marking conventions: phonetically unrealized elements

a.

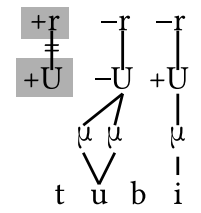

b.

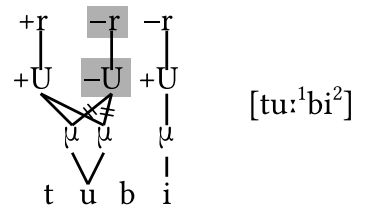

A central assumption in containment is that phonological constraints can refer to the unpronounced structure that is still part of the phonological representation. The additional representational complexity arising from unpronounced association lines and elements allows, for example, to predict opacity patterns (Goldrick 2000) or subtractive morphology from simple morpheme concatenation (Trommer \& Zimmermann 2014; Zimmermann 2017). More concretely, I adopt the 'Cloning Hypothesis' that every constraint exist in two versions: One is only sensitive to the phonetically interpreted structure and hence mirrors standard markedness constraints in correspondence theory. The other constraint-clon is a generalized version that is sensitive to all phonological structure, including phonetically invisible one (Trommer 2011; Trommer \& Zimmermann 2014). To ease readability, all constraints of the former type that are only sensitive to the phonetically interpreted structure are underlined in the following.

or non-invisible (or both). The latter more restrictive version would be relevant in the case studies in this paper (Zimmermann 2017). 


\subsection{Floating tones and overwriting}

In both of the analyses below, underlyingly floating tones trigger changes on the tonal melody of a base. In terms of autosegmental structure, this means that they associate to a base-TBU or base-tone feature and overwrite the underlying specification. The most crucial constraint family for such analyses are hence parsing constraints ensuring association of floating features, exemplified with (9a) that demands association of every $[+\mathrm{U}]$ feature to a $\mu$. Parsing constraints for the other tonal feature $[-\mathrm{U}],[+\mathrm{r}]$, and $[-r]$ are relevant in the analyses below as well.

Tableau (10) illustrates a basic overwriting configuration: a floating high tone 1 specified for $[+\mathrm{U},+\mathrm{r}]$ is adjacent to a morpheme beginning with a TBU specified for a low tone 4 , hence $[-\mathrm{U},-\mathrm{r}]$. The candidate (10a) that leaves the underlyingly unassociated tonal features 'floating', hence does not integrate them into the structure, fatally violates $+\mathrm{U}>\mu$ since $[+\mathrm{U}]$ is not linked to a $\mu$. This violation is avoided by candidate (10b) that links the tone to the initial $\mu$ via an epenthetic association line. However, such a structure is a true contour tone since two tonal features are linked to a single TBU. Contour tones are illicit both in MIB and MacZ and the constraint excluding them $* \mathrm{U}_{\mu} \mathrm{U}(9 \mathrm{~b})$ is taken to be undominated in both of the following analyses. ${ }^{6}$ Since $*{ }^{*} \mu^{U}$ is formulated over phonetically visible structure only, a violation can be avoided if the underlying association to $[-\mathrm{U}]$ is marked as phonetically invisible $(10 \mathrm{c})$. The $[+\mathrm{U}]$ is now phonetically associated with the initial $\mu$ and the underlying initial tone is 'overwritten'. The contrast between candidates (10a) and (10c) illustrates the key logic that underlies overwriting in containment: whereas a $[ \pm$ Upper $]$ and a $[ \pm$ raised] feature remains phonetically uninterpreted in both candidates, (10c) has a better constraint profile than (10a) since both $[ \pm$ Upper] features are integrated into the structure by at least a phonetically invisible association. Both candidates hence only fare identical with respect to MAx[r] (9c) and MAx[U] (9d) penalizing phonetically unrealized features, they differ crucially in their satisfaction of $+\mathrm{U}>\mu$.

(9) a. $\quad+\mathrm{U}>\mu$ : Assign $*$ for every $[+\mathrm{U}]$ that is not associated to a $\mu$.

b. $* \mathrm{U}_{\mu} \mathrm{U}$ : Assign $*$ for every $\mu$ that is phonetically visibly linked to two features $[ \pm \mathrm{U}]$.

c. $\operatorname{Max}[\mathrm{r}]:$ Assign * for every phonetically invisible $[ \pm \mathrm{r}]$.

d. Max[U]: Assign * for every phonetically invisible $[ \pm \mathrm{U}]$.

${ }^{6}$ Association of both $[+\mathrm{r}]$ and $[-\mathrm{r}]$ to a $[ \pm \mathrm{U}]$ would also result in a contour tone. The counterpart to $(9),{ }^{* \mathrm{R}} \mathrm{U}^{\mathrm{R}}$ is hence also undominated and association of floating $[ \pm \mathrm{r}]$ features results overwriting as well in the analyses below. 
To ease readability, the phonetic output tones resulting from the phonological structure of every candidate are given in brackets below every TBU.

(10) Overwriting

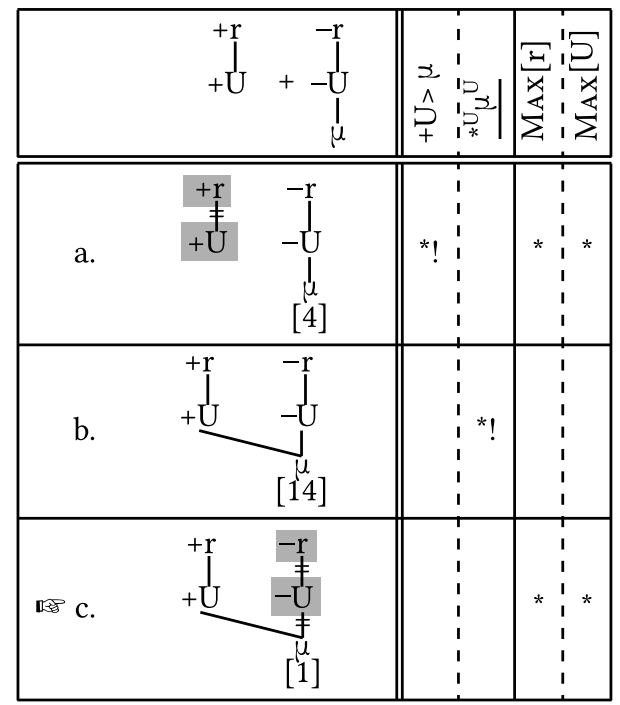

This general overwriting logic is the background for the following analyses. Another constraint relevant for the realization of floating tones is Alternation (11) that penalizes association of an element to another element belonging to the same morpheme (van Oostendorp 2007; 2012). Since high-ranked Alternation hence only allows association between elements across a morpheme boundary, it predicts a variety of morphologically Derived Environment Effects (Lubowicz 2002; Burzio 2011). AlTERNATION is taken to be undominated in both of the following analyses and a floating feature can thus never associate to a TBU or any other element of the morpheme it belongs to.

(11) Alternation (= Alt): Assign * for every epenthetic association line between elements of the same morphological colour.

Both case studies differ in how (non)local the association of floating tones can be, i.e., whether a floating tone can be realized on a non-adjacent TBU. In MIB, tone association is strictly local and only has indirect non-local effects but in MacZ, potentially non-local association of tonal features exists. In containment theory, any literal reordering of elements is impossible (van Oostendorp 2006; Zimmermann \& Trommer 2013). Since morphemes are taken to enter the phonology fully linearized, the prefixed floating tonal 
features in MIB and MacZ hence precede all other tonal features of their base. A preference for association to an adjacent host under these assumptions follows from *CROss banning crossing of association lines (Goldsmith 1976). Crucially, ${ }^{*}$ Cross in (12a) is a generalized version that sees all phonological structure, including phonetically invisible one: An underlying association line can hence block association 'across' it, even if it is not realized. In all following analyses, crossing of two phonetically visible association lines is never considered: Whether it is ruled out by GEN as is usually assumed or by another violable constraint (= the phonetic clone of (12a)) that is undominated in MIB and MacZ is a question which is orthogonal to the present discussion. The existence of (12a) does not imply the existence of phonetically visible line crossing, it simply penalizes the generalized structure where any association lines cross. A second relevant markedness constraint excluding some association possibilities of floating tones is *SHIFT (12b) penalizing shifting of tone features.

(12) a. *Cross: Assign * to every sequence of TBU's $X$ and $Y$ if $X$ precedes $Y$ and $X$ is associated to tone $\mathrm{T}_{2}$ and $Y$ to tone $\mathrm{T}_{1}$ and tone $\mathrm{T}_{1}$ precedes $\mathrm{T}_{2}$.

b. *Shift: Assign * to every element $A$ linked to element $X$ via an underlying but phonetically invisible association and to element $Y$ via an inserted association line if $X$ and $Y$ are on the same tier $n$.

The effect of both constraints is illustrated in (13) where different association possibilities for a floating tone feature $[+r]$ are shown. It can either associate locally to the first register feature that is associated to the $[ \pm \mathrm{r}]$ feature adjacent to the floating feature $(13 \mathrm{~b})$ or it can associate non-locally across an underlying $[ \pm \mathrm{r}]$ feature $(13 \mathrm{c})$. Such a non-local association crucially implies non-realization of the intervening $[ \pm r]$ feature $(s)$ but induces a violation of ${ }^{*}$ CROss. Note that under standard correspondence theory, the structure in (13c) would never be characterized as line crossing simply because the unrealized association line would be deleted. Only in containment theory where any deletion of structure is impossible can a generalized version of ${ }^{*}$ CROss prefer local association. Candidate (13d), finally, involves local association of the floating $[+\mathrm{r}]$ but nevertheless has an indirect non-local effect since the $[-\mathrm{U}]$ to which the floating feature associates shifts to an adjacent TBU. This induces a violation of *SHIFT. Structure (13d) will become especially important in the analysis of floating tones in MIB (section 3.2) and (13c) in the analysis of floating tones in MacZ (section 4.2). ${ }^{7}$

${ }^{7}$ In the following tableaux, the input is omitted since it can easily be reconstructed from possible output structures in containment theory. 
(13) Local overwriting

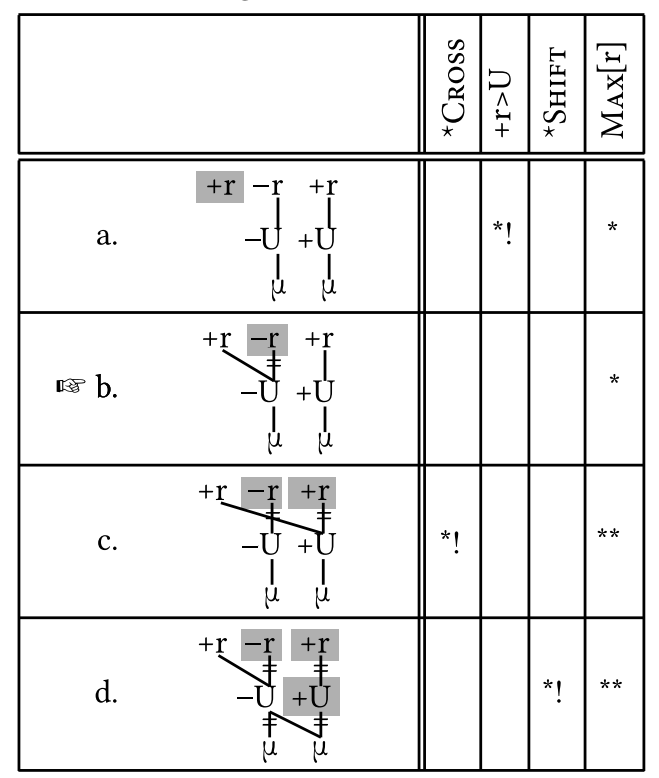

A final markedness constraint on autosegmental structure that is crucial in the following analyses is (14) penalizing redundant double association of the same element to an element on another tier. The version relevant in the following refers to identical values for identical features: It hence penalizes association of more than one $[+r]$ or more than one $[-r]$ feature to $[ \pm \mathrm{U}]$ and association of more than one $[+\mathrm{U}]$ or more than one $[-\mathrm{U}]$ feature to a $\mu$. In contrast to $* \mathrm{U}_{\mu}^{\mathrm{U}}$ and ${ }^{* \mathrm{r}} \mathrm{U}^{\mathrm{r}}$ (cf. $\left.(9 \mathrm{~b})\right)$ it hence not only penalizes double association of two elements from the same tier to one host but only association of identical elements. As ${ }^{*}$ CROSs, it is a generalized containment constraint that is sensitive to all structure. Non-realization of underlying association lines will hence not help in avoiding a violation of this constraint.

(14) ${ }^{*} \alpha \mathrm{A} \alpha \mathrm{A}$ : Assign $*$ for every element associated to more than one $\alpha \mathrm{A}$ elements.

Its effect is briefly illustrated in (15): if the adjacent TBU is underlyingly specified for $[+\mathrm{U}]$, every association of a floating $[+\mathrm{U}]$ to this TBU will induce a violation of $* \alpha \mathrm{A} \alpha \mathrm{A}$. The relation to the phonetic version of $* \mathrm{U}_{\mu}^{\mathrm{U}}$ $(9 \mathrm{~b})$ is also shown in (15): every violation of ${ }^{*} \alpha \mathrm{A} \alpha \mathrm{A}$ implies a violation of $* \mathrm{U}_{\mu} \mathrm{U}$ but the phonetic version of the anti-contour tone constraint $* \mathrm{U}_{\mu} \mathrm{U}$ can be avoided via marking one association line as invisible (15c). Such a 
strategy is not helpful for the generalized version ${ }^{*} \alpha \mathrm{A} \alpha \mathrm{A}$ that is sensitive to all types of association lines.

(15) No redundant association

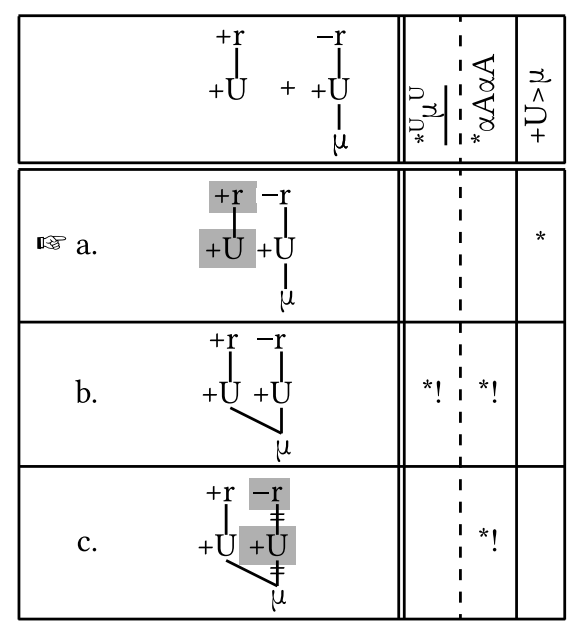

$*_{\alpha \mathrm{A}} \alpha \mathrm{A}$ will become particularly crucial in the analysis for MIB in section 3 where complex structures of multiple floating tonal elements are assumed and the choice of which one of these features can be realized is mainly due to $* \alpha \mathrm{A} \alpha \mathrm{A}$.

\section{Floating tones in San Esteban Atatláhuca}

\subsection{Data}

San Esteban Atatláhuca (= MIB) is a Mixtec language spoken in the West of Oaxaca, México (Mak 1953; Alexander 1980; Alexander \& Mak 2009; McKendry 2013). The language has four tone levels. Adjacent identical vowels are syllabified into different syllables (Alexander 1980, 7) and there are no long vowels. Consequently, there is no way to decide whether the TBU in MIB is the $\mu$ or the $\sigma$; for reasons of consistency with the following case study, tonal register features associate to the $\mu$ in the following. As can be seen in the table in (16), not all combinations of tones are attested underlyingly. Especially tone 3 is restricted and occurs only following tone 1 and tone 4 . In addition, there is no underlying 4.4 base in MIB. 
(16) Attested underlying bases (McKendry 2013, 48)

\begin{tabular}{|c||l|l|l|l|}
\hline & 4 & 3 & 2 & 1 \\
\hline \hline 4 & & $\begin{array}{l}\mathrm{te}^{4} \mathrm{e}^{3} \\
\text { 'man' }\end{array}$ & $\begin{array}{l}\mathrm{so}^{42} \mathrm{o}^{2} \\
\text { 'ear' }\end{array}$ & $\begin{array}{l}\mathrm{tu}^{4} \mathrm{u}^{1} \mathrm{n} \\
\text { 'turkey hen' }\end{array}$ \\
\hline 2 & $\begin{array}{l}\mathrm{k}^{\mathrm{w}} \mathrm{e}^{22} \mathrm{e}^{4} \\
\text { 'much' }\end{array}$ & $\begin{array}{l}\beta \mathrm{e}^{22} \mathrm{e}^{2} \\
\text { 'house' }\end{array}$ & $\begin{array}{l}\mathrm{nu}^{2} \mathrm{hi}^{1} \\
\text { 'chicken' }\end{array}$ \\
\hline 1 & $\begin{array}{l}\beta \mathrm{i}^{1}{ }^{1} \mathrm{li}^{4} \\
\text { 'toy' }\end{array}$ & $\begin{array}{l}\beta \mathrm{ii}^{1} \mathrm{ti}^{3}{ }^{3} \\
\text { 'fan' }\end{array}$ & $\begin{array}{l}\text { lu}{ }^{1} \mathrm{su}^{2} \\
\text { 'pet dog' }\end{array}$ & $\begin{array}{l}\mathrm{ne}^{12} \mathrm{e}^{1} \\
\text { 'blue' }\end{array}$ \\
\hline
\end{tabular}

As in nearly all Mixtec languages, there are several morphemes in MIB that trigger a tonal change (or 'perturbation') on a following morpheme (Pike 1944; Dürr 1987; Hollenbach 2003). Mak (1953) and McKendry (2013) differentiate three classes of morphemes: those that do not trigger any tonal change on a following word, those that have a raising effect (marked with superscripted ${ }^{b}$ ), and those that have a lowering effect (marked with superscripted $^{\mathrm{c}}$ ) on the tonal melody of the following word. ${ }^{8}$ Examples for these different morpheme types and their effect on the tonal melody of a following word are given in (17). Whereas $/ 2 \widetilde{\partial}^{2} \widetilde{\partial}^{2} /$ does not trigger any change on the tonal melody of a following word, an initial tone 2 is raised to tone 1 following a morpheme like $/ \mathrm{ta}^{4} \mathrm{ka}^{2(\mathrm{~b})} /(17 \mathrm{~b})$ and lowered to tone 3 following a morpheme like $/ \mathrm{P}^{2 \mathrm{n}} \mathrm{ga}^{2(\mathrm{c})} /(17 \mathrm{c})$.

(17) Tone perturbation (Mak 1953, 88-89)
Underlying
Surface
a. $\quad$ ?ว $\widetilde{\partial}^{2}{ }^{2} \mathrm{n}_{\mathrm{d} \partial}{ }^{2} \mathrm{~b} \partial^{4}$
1əว ${ }^{2} \widetilde{\partial}^{2} \mathrm{n}_{\mathrm{d} \partial}{ }^{2} \mathrm{bə}{ }^{4} \quad$ 'one egg'
b. $\mathrm{ta}^{4} \mathrm{ka}^{2(\mathrm{~b})} \mathrm{n}_{\mathrm{d} \curvearrowright^{2}} \mathrm{bə}^{4}$
ta ${ }^{4} \mathrm{ka}^{2} \mathrm{n}_{\text {də }}{ }^{1} \mathrm{bə}^{4}$ 'each egg'
c. Pə $^{2} \mathrm{nga}^{2(\mathrm{c}) \mathrm{n}_{\mathrm{də}}{ }^{2} \mathrm{bə}}{ }^{4}$

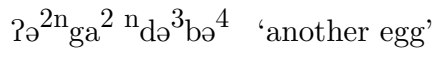

All tonal changes triggered by morphemes ${ }^{b}$ and morphemes ${ }^{c}$ are listed in (18) for all possible following tone specifications. It can be seen that the raising morphemes ${ }^{b}$ only trigger a change for words starting with a tone 4 and those with a 2.4 melody; all other words keep their tonal specification

${ }^{8}$ This distinction is a simplification since there are so called 'special sequences' (= syntactic configurations like noun and its modifier or certain verb+auxiliary complexes) that show different tonal changes. A complete account of all tonal facts in MIB goes unfortunately beyond the scope of the paper and I hence focus on the interesting tonal asymmetries that follow from sub-tonal features. 
faithfully. Lowering morphemes ${ }^{\mathrm{c}}$, on the other hand, leave all words starting with a tone 4 unperturbed but have effects for all words starting with a tone 1 or tone $2 .^{9}$

(18) Summary: tone perturbation

\begin{tabular}{|l|ll|ll|}
\hline Underlying & \multicolumn{2}{|c|}{ Lowering } & \multicolumn{2}{|c|}{ Raising } \\
\hline 1.1 & $\rightarrow$ & 3.1 & $\rightarrow$ & 1.1 \\
1.2 & $\rightarrow$ & 2.2 & $\rightarrow$ & 1.2 \\
1.3 & $\rightarrow$ & 2.3 & $\rightarrow$ & 1.3 \\
1.4 & $\rightarrow$ & 2.4 & $\rightarrow$ & 1.4 \\
\hline 2.1 & $\rightarrow$ & 3.1 & $\rightarrow$ & 2.1 \\
2.2 & $\rightarrow$ & 3.2 & $\rightarrow$ & 2.2 \\
2.4 & $\rightarrow$ & 3.4 & $\rightarrow$ & 1.4 \\
\hline 4.1 & $\rightarrow$ & 4.1 & $\rightarrow$ & 1.3 \\
4.2 & $\rightarrow$ & 4.2 & $\rightarrow$ & 1.3 \\
4.3 & $\rightarrow$ & 4.3 & $\rightarrow$ & 1.3 \\
\hline
\end{tabular}

These tonal changes are now a severe challenge for an analysis based on tone primitives in an autosegmental model. The two crucial parameters that any account has to predict are, first, the locus of the change, i.e., the question of where in the base a tonal change can be found, and, second, the nature of the change, i.e., the question which tones undergo which changes.

For the lowering morphemes ${ }^{\mathrm{c}}$, the first question is easy to answer since it is always the initial TBU that shows the change. In addition, all tones but the lowest show some lowering effect. The nature of the change, however, is asymmetric: The initial TBU of bases is lowered to tone 3 for bases starting with tone 2 and 1.1 bases but all other 1-initial bases show only a lowering to tone 2 . An autosegmental analysis based on tonal primitives apparently needs to assume at least two different representations for these morphemes: a floating 3 (19a) and a floating 2 (19b).

${ }^{9}$ The bases in the context of lowering morphemes are described in Mak (1953) as having "a lowering of their final toneme to $3[\ldots]$ with or without a monosyllabic glide back to the final toneme of the basic couplet"' (ibid., 91). Bases 4.1 are hence optionally lowered to $1.3^{4}$, bases 4.2 . to $1.3^{2}$ and 4.3 to $1.3^{2}$. It has to emphasized that this is apparently an optional variant and that contours/tonal glides only result from tone perturbation and are otherwise absent from MIB. In the following, I hence concentrate on the tonal changes in (18), although the account can in principle predict the contour variants as well (cf. footnote 12). 
(19) The lowering morphemes ${ }^{\mathrm{c}}$ as a challenge for tonal primitives

a. Lowering to $3: 1.1,2 . X \rightarrow 3.1,3 . X$

b. Lowering to $2: 1.2 / 3 / 4 \rightarrow 2.2 / 3 / 4$
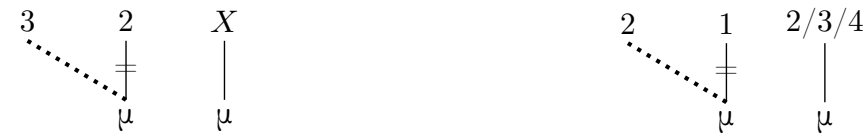

Table (20) summarizes all changes we find in the context of a lowering morphemes ${ }^{c}$ in MIB. The cells of the table give the resulting surface forms of the base; tonal changes are marked with a thick frame and the thickness of the frames differentiates the different types of changes.

(20) Changes of lowering morphemes ${ }^{\mathrm{c}}$

\begin{tabular}{|c|c|c|c|c|}
\cline { 2 - 5 } \multicolumn{1}{c|}{} & 1 & 2 & 3 & 4 \\
\hline 1 & 3.1 & 2.2 & 2 & 2 \\
\hline 2 & 3.1 & 3.2 & & 3.4 \\
\hline 4 & 4.1 & 4.2 & 4.3 & \\
\hline
\end{tabular}

For the raising morphemes ${ }^{\mathrm{b}}$, the locus of the tonal change is not as clear since it sometimes affects only the initial and sometimes the initial and the second TBU of a following word. Whereas a change on the initial TBU consistently results in the highest tone 1 , the second TBU is changed to 3 . The main challenge of the raising morphemes is hence the question why they sometimes affect the whole tonal melody of a base (in 4.1 and 4.2 bases) but sometimes only the initial TBU (in 2.4 and 4.3 bases). A possible account under the assumption of floating primitive tones is given in (21): An additional tone 3 only links to the second TBU in the contexts $(21 \mathrm{~b}),{ }^{10}$ not in the context (21a).

(21) The raising morphemes ${ }^{b}$ as a challenge for tonal primitives

a. No change for second TBU:

$2.4 \rightarrow 1.4 ; 4.3 \rightarrow 1.3$

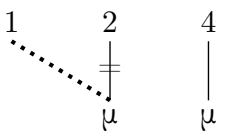

b. Lowering of second TBU:

$4.1 / 2 \rightarrow 1.3$

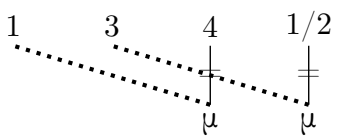

${ }^{10}$ Which strategy applies can of course not be decided for 4.3 bases since the expected change and the underlying tone are identical. 
An additional challenge for the raising morphemes ${ }^{\mathrm{b}}$ is that some bases do not undergo any change at all. This might be expected for bases that already begin with the highest tone 1 but is unexpected for 2.1 and 2.2 bases. Table (22) summarizes the effect of raising morphemes for all tonal bases.

(22) Changes of raising morphemes ${ }^{b}$

\begin{tabular}{|l|c|c|c|c|}
\cline { 2 - 5 } \multicolumn{1}{c|}{} & 1 & 2 & 3 & 4 \\
\hline 1 & 1.1 & 1.2 & 1.3 & 1.4 \\
\hline 2 & 2.1 & 2.2 & & 1.4 \\
\hline 4 & 1.3 & 1.3 & 1 & \\
\hline
\end{tabular}

\subsection{Tone feature analysis}

In the following, it is shown how the asumption of sub-tonal features allows a straightforward account of the raising and lowering effects in MIB. The decomposition into tonal features assumed for MIB is repeated in (23) from 4. Especially crucial are the two underspecifed tones $[+\mathrm{U}]$ and $[-\mathrm{U}]$ that are assumed to be interpreted as 1 and 3 respectively, hence with a default $[+\mathrm{r}]$ feature.

(23) Tones in MIB

\begin{tabular}{|r|r|r|r|c|c|}
\hline $\mathbf{4}$ & $\mathbf{3}$ & $\mathbf{2}$ & $\mathbf{1}$ & $\mathbf{3}$ & $\mathbf{1}$ \\
\hline \hline $\begin{array}{r}-\mathrm{r} \\
\mid\end{array}$ & $+\mathrm{r}$ & $-\mathrm{r}$ & $+\mathrm{r}$ & & \\
$-\mathrm{U}$ & $-\mathrm{U}$ & $+\mathrm{U}$ & $\mid+\mathrm{U}$ & $-\mathrm{U}$ & $+\mathrm{U}$ \\
\hline
\end{tabular}

The floating tones triggering the changes of perturbing morphemes in MIB are given in (24). All morphemes triggering a lowering effect on a following morpheme are assumed to contain a floating $[-\mathrm{r}]$ and $[-\mathrm{U}]$ feature in their representation (24a). As is shown in the next section 3.2.1, the interaction of standard faithfulness and markedness constraints introduced in section 2.3 predicts that the two features are in complementary distribution: either the $[-\mathrm{U}]$ associates to the initial TBU causing an underspecified tone 3 or the floating $[-\mathrm{r}]$ associates to an initial underlying $[+\mathrm{U}]$ feature resulting in a tone 2 . All morphemes causing a raising effect on the following morpheme, on the other hand, contain a floating fully specified $[+\mathrm{U},+\mathrm{r}]$ and a floating $[+\mathrm{r}]$ feature $(24 \mathrm{~b})$. This complex structure predicts indirect 
non-local tonal effects: whereas the fully specified tone 1 associates to the initial TBU, the floating register feature $[+\mathrm{r}]$ can have a raising effect on the second TBU via shifting.

The most crucial constraint blocking realization of these floating tonal features for certain bases is $* \alpha \mathrm{A} \alpha \mathrm{A}$ penalizing double redundant association of the same feature.

(24) Representation of perturbing morphemes

a. Lowering b. Raising

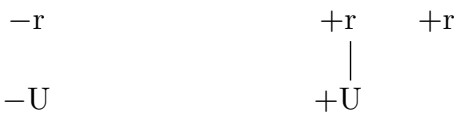

\subsubsection{Lowering morphemes}

The realization of the two floating features $[-\mathrm{U}]$ and $[-\mathrm{r}]$ causing lowering is ensured by the parsing constraints $-r>U$ and $-U>\mu$. However, a first important observation is that those two features are not underlyingly associated. Given that Alternation (=Alt; (11)) is undominated in MIB, they can never be associated to each other. Another important background assumption about MIB is that association of floating tones is always local; ${ }^{*}$ Cross (12) is hence taken to be undominated in MIB. The effect of these two undominated constraints is shown in (25) for a base with tone melody 2.1. Realization of both floating features via associating the floating $[-\mathrm{r}]$ to floating $[-\mathrm{U}]$ as in $(25 \mathrm{~b})$ is excluded by Alt. Association of the floating $[-\mathrm{r}]$ to the second $[+\mathrm{U}]$ feature of the base in $(25 \mathrm{c})$, on the other hand, implies non-realization of the intervening $[-\mathrm{r}]$ feature and fatally violates ${ }^{*}$ Cross. In all following tableaux, no candidates violating ${ }^{*}$ CROSS or ALT are hence considered. Recall that the segmental portion of the morphemes triggering the tonal change are ignored in the following and only the floating tone portion and the base it is adjacent to are given in all following tableaux.

After establishing the complementary distribution of both floating features, we can now turn to the specific predictions they have for bases with different forms. In MIB, $-r>U$ is taken to be ranked above $-U>\mu$ and realization of the floating register feature $[-\mathrm{r}]$ is hence in principle preferred over realization of $[-\mathrm{U}]$. Only when realization of $[-\mathrm{r}]$ is impossible, can $[-\mathrm{U}]$ associate and overwrite the tone feature of the initial TBU. A crucial constraint that blocks association of the floating tone features in some contexts is $* \alpha \mathrm{A} \alpha \mathrm{A}$ penalizing redundant feature association. How this general logic derives all surface effects of the lowering morphemes is shown in the following tableaux. We will start with contexts where this effect of 
(25) Excluded realization of the floating feature

\begin{tabular}{|c|c|c|c|}
\hline & 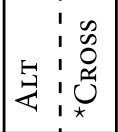 & $\frac{2}{x}$ & $\underset{\exists}{z}$ \\
\hline 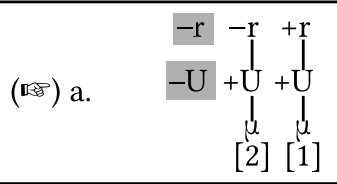 & $\begin{array}{l}1 \\
1 \\
1 \\
1 \\
1 \\
1\end{array}$ & * & * \\
\hline 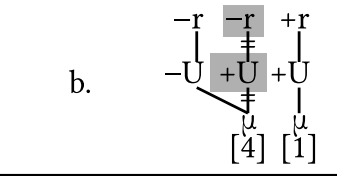 & \begin{tabular}{l|l}
$*$ & 1 \\
&
\end{tabular} & * & * \\
\hline 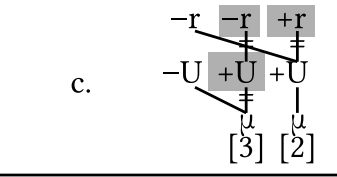 & $\begin{array}{l}1 \\
1 \\
1 \\
1 \\
1 \\
1 \\
1\end{array}$ & * & ** \\
\hline
\end{tabular}

${ }^{*} \alpha \mathrm{A} \alpha \mathrm{A}$ is crucial and excludes association for one or all of the floating features. If the following TBU starts with a tone 2 that is specified for $[-\mathrm{r}],{ }^{*} \alpha \mathrm{A} \alpha \mathrm{A}$ blocks association of the $[-\mathrm{r}]$ as in candidate $(26 \mathrm{c})$ and only $[-\mathrm{U}]$ overwrites the initial tone. An underspecified tone 3 hence results in the winning candidate (26b).

Since there are no bases starting with a tone 3 , the only other context where ${ }^{*} \alpha \mathrm{A} \alpha \mathrm{A}$ directly blocks association of the floating tone features are bases starting with a tone $4(27)$. In this context, the initial TBU is already specified for tonal features identical to the two floating features. ${ }^{*} \alpha \mathrm{A} \alpha \mathrm{A}$ hence excludes realization of both these features since association of [-U] $(27 \mathrm{~b})$ and $[-\mathrm{r}](27 \mathrm{c})$ results in a redundant double association. In the winning candidate (27a), both features hence remain floating.

In a context where the following base starts with a tone 1 that is specified for the complementary features $[+\mathrm{U}]$ and $[+\mathrm{r}]$, on the other hand, ${ }^{*} \alpha \mathrm{A} \alpha \mathrm{A}$ is irrelevant and both floating features can in principle associate. Neither realization of $[-\mathrm{U}](28 \mathrm{~b})$ nor realization of $[-\mathrm{r}](28 \mathrm{c})$ violates $*_{\alpha \mathrm{A}} \alpha \mathrm{A}$. The competition is hence decided by the ranking of $-\mathrm{r}>\mathrm{U}$ over $-\mathrm{U}>\mu$ and (28b) becomes optimal. The stepwise lowering effect in MIB is hence an epiphenomenon from two different floating 'low' features: tones 2 become tone 3 after association of $[-\mathrm{U}](26)$ and tones 1 become tone 2 after association of $[-r](28)$. 
(26) $2 . X$ - Only [-U] can associate

\begin{tabular}{|c|c|c|c|c|}
\hline & $\underset{*}{\underset{\delta}{8}}$ & $\begin{array}{l}\hat{n} \\
\dot{\dagger}\end{array}$ & $\begin{array}{l}\Omega \\
\hat{\rho} \\
\hat{\rho}\end{array}$ & 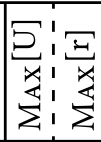 \\
\hline 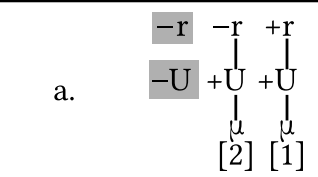 & & * & *! & $\begin{array}{c:c}1 \\
* \\
\vdots \\
1\end{array}$ \\
\hline 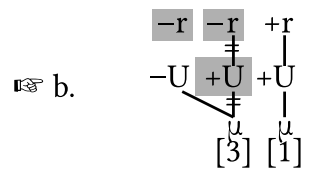 & & * & & $\begin{array}{c:}1 \\
*_{1} \\
\vdots \\
1\end{array}$ \\
\hline 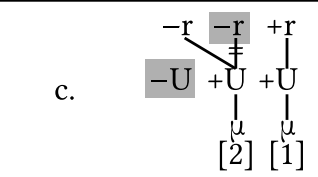 & *! & & * & $\begin{array}{c}1 \\
1 \\
* \\
1 \\
1 \\
1\end{array}$ \\
\hline
\end{tabular}

(27) 4.X - No change

\begin{tabular}{|c|c|c|c|c|}
\hline & 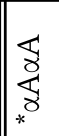 & $\stackrel{\sim}{i}$ & $\begin{array}{l}x \\
\hat{s} \\
\hat{s}\end{array}$ & : \\
\hline 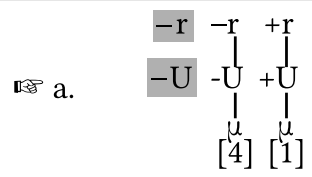 & & * & * & $\begin{array}{r}1 \\
1 \\
* \\
1 \\
1 \\
1\end{array}$ \\
\hline 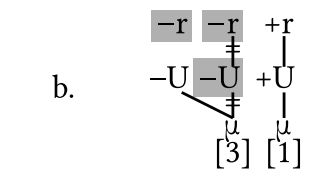 & *! & * & & $\begin{array}{c:}1 \\
\\
* \\
1 \\
1 \\
1\end{array}$ \\
\hline 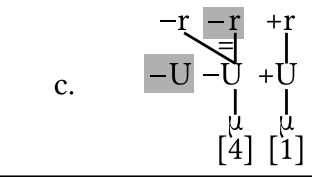 & ${ }^{*} !$ & & * & $\begin{array}{rr}1 \\
1 \\
* 1 \\
1 \\
1 \\
1\end{array}$ \\
\hline
\end{tabular}


(28) 1.2 - Preference for realizing $[-r]$

\begin{tabular}{|c|c|c|c|c|}
\hline & 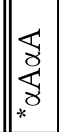 & 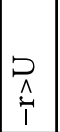 & $\begin{array}{l}x_{1} \\
\hat{n} \\
\hat{1}\end{array}$ & 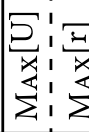 \\
\hline 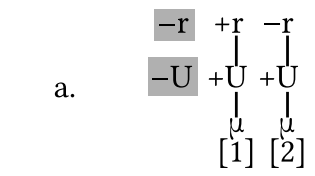 & & ${ }^{*} !$ & * & $\begin{aligned} 1 \\
* \\
* \\
1 \\
1 \\
1\end{aligned}$ \\
\hline 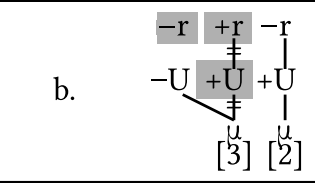 & & *! & & $\begin{array}{c}1 \\
\text { * } \\
1 \\
1 \\
1 \\
1\end{array}$ \\
\hline 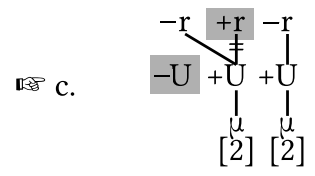 & & & * & $\begin{array}{r}1 \\
\vdots \\
* \\
1 \\
1 \\
1\end{array}$ \\
\hline
\end{tabular}

This analysis hence predicts a change to tone 2 for all bases starting with tone 1. This prediction is borne out for all bases except for ones with a tonal melody 1.1 that show a change to 3.1, not 2.1. This exceptional behaviour follows, it is argued, since those bases have a double association of a single tonal representation to two TBU's. ${ }^{11}$ Those are subject to the special faithfulness constraint (29) that preserves the register feature of long tones. In a double association context, $[-\mathrm{U}]$ hence associates as in winning candidate (30b) despite the general preference for [-r]-realization. This preferred strategy simply induces a fatal violation of $\operatorname{ID}\left[\mathrm{U}_{\mu \mu}\right](30 \mathrm{a})$ since the $[+\mathrm{U}]$ is linked to two $\mu$ 's. Since the containment-based version of (29) is insensitive to the phonetic visibility of the double association, marking one of the associations to the underlying $[-\mathrm{U}]$ as phonetically invisible as in candidate (30c) is not a helpful repair.

(29) $\operatorname{ID}[\mathrm{U} \mu \mu]$ : Assign * for every epenthetic association line between $[ \pm \mathrm{U}]$ and $[ \pm \mathrm{r}]$ if $[ \pm \mathrm{U}]$ is linked to more than one TBU.

${ }^{11}$ Richness of the base predicts that bases with two adjacent identical tones are possible underlying structures. It is assumed that all such structures are excluded by the OCP at an earlier optimization level. A stratal architecture is hence assumed with a pre-optimization cycle applying before morphemes are concatenated (Trommer 2011; Bermúdez-Otero in preparation). Not only adjacent identical tones are neutralized to double-associated ones, underspecified TBU's are also repaired at this earlier stratum. 
(30) 1.1 - Preservation of long tone features and only [-U] associates

\begin{tabular}{|c|c|c|c|c|c|}
\hline & 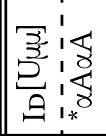 & $\stackrel{\sim}{\hat{\imath}}$ & 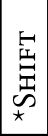 & 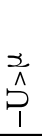 & 雪: \\
\hline a. $\quad \overbrace{-U}^{-\mathrm{U}} \overbrace{\substack{\mu \\
[2][2]}}^{+\mathrm{r}}$ & $\begin{array}{r}1 \\
\vdots \\
* \\
\vdots \\
1 \\
1 \\
1\end{array}$ & & & * & $\begin{array}{c}1 \\
\vdots \\
1 \\
1 \\
1\end{array}$ \\
\hline $\mathrm{b} . \quad \underbrace{+\mathrm{U}}_{\left[\begin{array}{c}\mu \\
3]\end{array}\right][1]}$ & $\begin{array}{l}1 \\
1 \\
1 \\
1\end{array}$ & * & & & $\begin{array}{c}1 \\
\vdots \\
i \\
i\end{array}$ \\
\hline 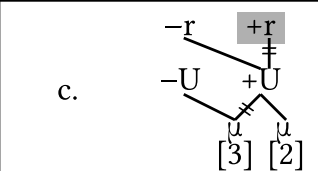 & $\begin{array}{r}1 \\
\vdots \\
\vdots \\
\vdots \\
\vdots \\
1\end{array}$ & & & & $\begin{array}{r}1 \\
\vdots \\
\vdots \\
\vdots \\
1\end{array}$ \\
\hline
\end{tabular}

This special faithfulness constraint is of course also relevant in 2.2 contexts. It does, however, not make any additional interesting prediction in these contexts since association of $[-r]$ as in (31a) is independently excluded by $* \alpha \mathrm{A} \alpha \mathrm{A}$.

(31) 2.2 - Only [-U] can associate

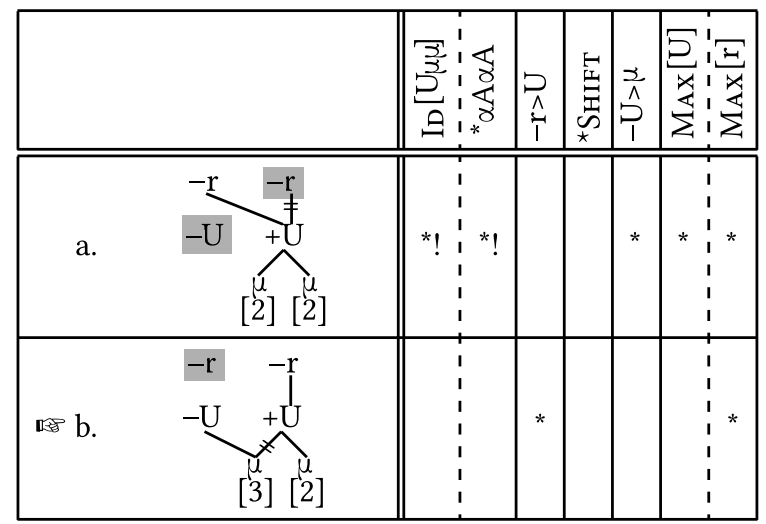

At the beginning of this section, it was emphasized that only one of the two floating tonal features of a lowering context can be realized. The main reason for this complementary distribution is the high position of both

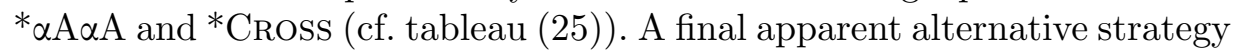


we have to consider is tone shifting: could that not help realizing both features in certain contexts? A relevant context is given in (32) where a base starting with a tone 1 followed by a tone 3 is optimized. In (28), we saw that only realization of $[-r]$ and hence lowering to a tone 2 becomes optimal for bases starting with a tone 1 (32b). A crucial competitor in this case is candidate $(32 \mathrm{c})$ that realizes both floating features and hence avoids the violation of $-\mathrm{U}>\mu$ that $(32 \mathrm{~b})$ induces. This realization of both floating features implies shifting of the feature $[+\mathrm{U}]$ underlyingly associated to the initial base-TBU to the second TBU: An indirect non-local effect of the floating $[-\mathrm{r}]$ hence surfaces. However, the only violation this candidate helps to avoid compared to the winning candidate (32b) is a violation of $-\mathrm{U}>\mu$ and this constraint is crucially dominated by *SHIFT. Tone shifting resulting in an indirect non-local effect on a non-initial TBU is hence excluded for lowering contexts.

(32) $1.3 / 4$ - No shifting

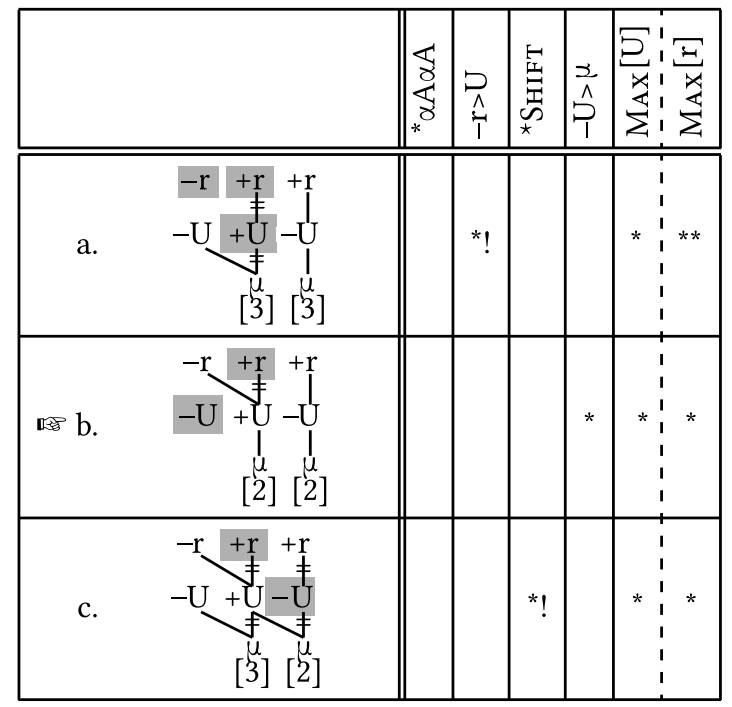

For 1.2 bases (28), shifting is independently excluded by ${ }^{*} \alpha \mathrm{A} \alpha \mathrm{A}$ as well: the second TBU is already specified for $[+\mathrm{U}]$ and the initial $[+\mathrm{U}]$ can hence not associate to this TBU as well. The shifting strategy is also independently excluded for bases starting with any tone other than 1 since association of floating $[-\mathrm{U}]$ to the initial TBU's specified for tone $4(=[-\mathrm{U}])$ and of $[-\mathrm{r}]$ to initial TBU's specified for tone $2(=[-\mathrm{r}])$ is excluded by $* \alpha \mathrm{A} \alpha \mathrm{A}$. The table in (33) summarizes this analysis for lowering morphemes in MIB 
based on the assumption of a floating $[-\mathrm{U}]$ and a floating $[-\mathrm{r}]$ and lists all tableaux and predicted effects for all base specifications.

(33) Changes of lowering morphemes ${ }^{\mathrm{c}}$

\begin{tabular}{|l||l|l|l|l|}
\hline & 1 & 2 & 3 & 4 \\
\hline \hline 1 & Only [-U] (30) & \multicolumn{3}{|c|}{ Only [-r] (28), (32) } \\
\hline 2 & Only [-U] (26) & Only [-U] (31) & Only [-U] (26) \\
\hline 4 & \multicolumn{3}{|c|}{ No association (27) } & \\
\hline
\end{tabular}

All the tonal changes triggered by raising morphemes are repeated in (34) for convenience. The claim is that this apparently challenging combination of changes falls out in a purely phonological account from the representation in (35) that is taken to be part of all underlying representations for a raising morpheme. This complex floating tonal structure contains a fully specified floating tone 1 and a tonal register feature $[+r]$.

(34) Changes of raising morphemes ${ }^{b}$

\begin{tabular}{|c|c|c|c|c|}
\hline & 1 & 2 & 3 & 4 \\
\hline 1 & 1.1 & 1.2 & 1.3 & 1.4 \\
\hline 2 & 2.1 & 2.2 & & 1.4 \\
\hline 4 & 1.3 & 1.3 & 1.3 & \\
\hline
\end{tabular}

(35) Raising morpheme

$$
{ }_{+\mathrm{U}}^{+\mathrm{r}}+\mathrm{r}
$$

The relevant parsing constraints ensuring realization of these floating tones are $+\mathrm{U}>\mu$ and $+\mathrm{r}>\mathrm{U}$, the counterparts to $-\mathrm{U}>\mu$ and $-\mathrm{r}>\mathrm{U}$. A first crucial difference to the lowering contexts above is the possibility of feature shifting. Since both these parsing constraints are ranked above *SHIFT, we see feature shifting in order to ensure that both tonal feature (bundles) can associate to the following morpheme. On the other hand, ${ }^{*} \alpha \mathrm{A} \alpha \mathrm{A}$ is undominated in MIB and redundant double feature associations are excluded, which seriously restricts the possibilities both features have to be realized. One context where the ideal sitation of realizing both floating tonal features is predicted is a 4.1 base as shown in (36). Candidate (36a) that leaves both tones floating induces fatal violations of both $+\mathrm{U}>\mu$ and $+r>$ U. Candidate (36b) associates only the first half of the floating tone: $[+\mathrm{U},+\mathrm{r}]$ associates to the initial TBU and hence overwrites the underlying tone associated to this TBU. Realization of the other floating tonal portion can be seen in $(36 \mathrm{c})$ where $[+\mathrm{r}]$ associates to the initial $[-\mathrm{U}]$, overwriting the underlying $[-r]$. Since $+r>U$ is higher-ranked than $+U>\mu$, this candidate already has a better violation profile than (36b). Candidate (36d), 
however, has an even better constraint profile since it basically combines both strategies and hence avoids the violation of both $+\mathrm{r}>\mathrm{U}$ and $+\mathrm{U}>\mu$.

(36) $4.1 / 2$ - Realization of all floating tonal features

\begin{tabular}{|c|c|c|c|c|c|}
\hline & 文 & $\begin{array}{l}x \\
\hat{A} \\
\hat{+}\end{array}$ & $\stackrel{D_{\hat{H}}}{+}$ & $\underline{y}$ & 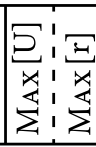 \\
\hline 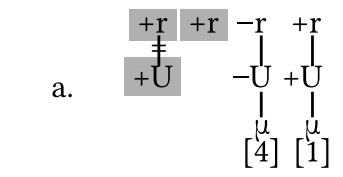 & & ${ }^{*} !$ & * & & * $\begin{array}{c}1 \\
1 \\
1 \\
1 \\
1\end{array}$ \\
\hline 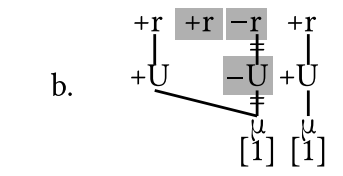 & & & *! & & $\begin{array}{c}1 \\
1 \\
1 \\
1 \\
1 \\
1\end{array}$ \\
\hline 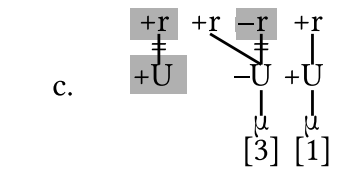 & & *! & & & * $\begin{array}{c}1 \\
\vdots \\
1 \\
1\end{array}$ \\
\hline 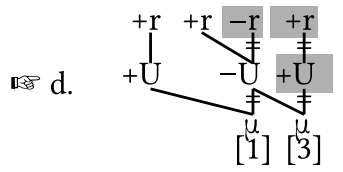 & & & & * & {$\left[\begin{array}{c}1 \\
1 \\
1 \\
1 \\
1 \\
1\end{array}\right.$} \\
\hline
\end{tabular}

Crucially, realization of both the floating $[+\mathrm{r}]$ and $[+\mathrm{U},+\mathrm{r}]$ implies shifting: $[+\mathrm{r}]$ associates to the underlyingly initial $[-\mathrm{U}]$ feature that in turn associates to the second TBU. This reassociation is necessary since the floating $[+\mathrm{U},+\mathrm{r}]$ already associates to the initial TBU and only one $[ \pm \mathrm{U}]$ feature can be associated to one $\mu$ (cf. (10)). Realization of the floating $[+\mathrm{r}]$ hence has an indirect non-local effect on the second TBU via shifting of a register feature. ${ }^{12}$ Comparing the violation profiles of $(36 \mathrm{~b})$ and (36c) reveals the importance of the containment assumption again: Although in both candidates, a [ $+\mathrm{r}]$-feature is not realized, only the former violates the parsing constraint $+\mathrm{r}>\mathrm{U}$. In the latter, the unrealized $[+\mathrm{r}]$ is underlyingly

${ }^{12}$ Recall that optional tone gliding can be observed on the second tone in those contexts (cf. footnote 9), i.e., 4.1 results in $1.3^{1}$ and 4.2 in $1.3^{2}$. These facts are predicted if the underlying tone of the second TBU is not completely overwritten $\left(={ }^{*} \mathrm{U}_{\mu} \mathrm{U}\right.$ is hence not high-ranked). The only challenge under this approach is the optional gliding for 4.3 bases that is $1.3^{2}$ and not the expected $* 1.3^{4}$. 
associated to $[+\mathrm{U}]$ and this underlying association will always ensure that it never violates $+\mathrm{r}>\mathrm{U}$ : the constraint is satisfied by any association line.

In (37), a base with an underlying 2.4 melody follows the floating tones. In such a context, the floating $[+\mathrm{U},+\mathrm{r}]$ has no chance to associate since the initial TBU is already $[+\mathrm{U}]$. Given that it can not associate to the second TBU due to ${ }^{*}$ Cross (cf. (25)), a violation of $+\mathrm{U}>\mu$ is hence unavoidable. It has to be emphasized that shifting of the underlyingly initial $[+\mathrm{U}]$, parallel to candidate $(36 \mathrm{~d})$ would not help in the slightest since it would still violate ${ }^{*} \alpha \mathrm{A} \alpha \mathrm{A}$. Floating $[+\mathrm{r}]$, on the other hand, can be realized and associates to the initial $[+\mathrm{U}]$. For an initial TBU that is already associated to a $[+\mathrm{U}]$ register feature, only a single tone change is hence expected, namely raising to 1 .

(37) 2.4 - No chance to realize $[+\mathrm{U},+\mathrm{r}]$

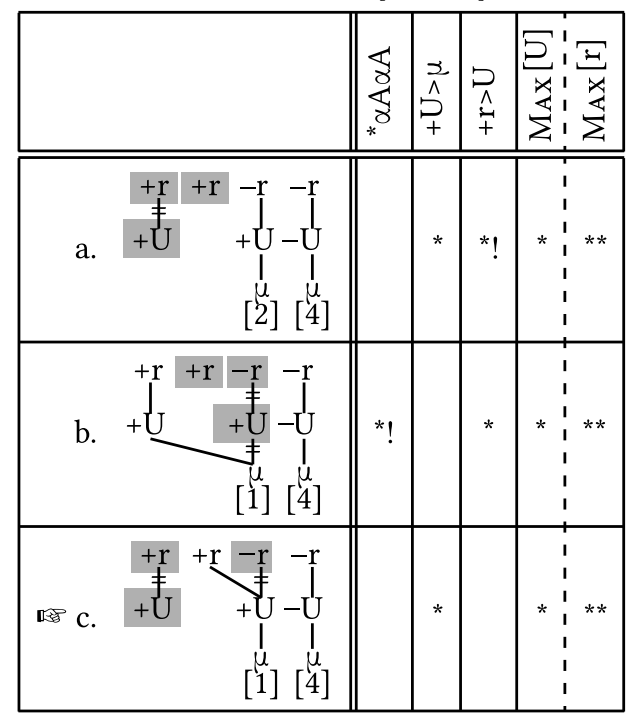

An expected counterpart where $* \alpha A \alpha$ A blocks association of $[+\mathrm{r}]$ but allows association of $[+\mathrm{U},+\mathrm{r}]$ is absent in MIB since there are no bases starting with a tone 3 that would have exactly such a specification of $[-\mathrm{U}]$ and $[+\mathrm{r}]$. Complete blocking of any association by ${ }^{*} \alpha \mathrm{A} \alpha \mathrm{A}$, on the other hand, is expected for 1.1-bases (38): Association of both floating features results in a fatal violation of ${ }^{*} \alpha \mathrm{A} \alpha \mathrm{A}$ and the candidate with two floating structures (38a) wins the competition. 
(38) 1.X - No association possible

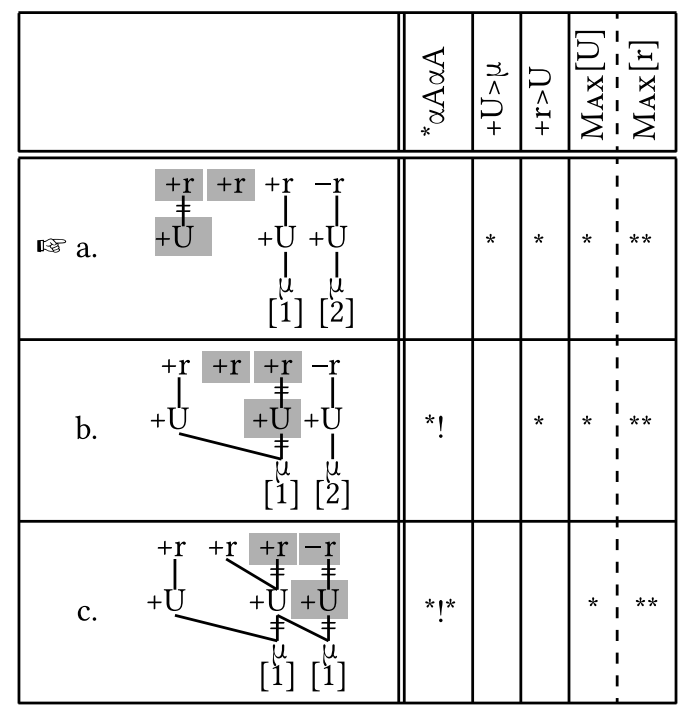

A final interesting context are 4.3 bases. The initial TBU is specified for the complementary features $[-\mathrm{U}]$ and $[-\mathrm{r}]$ as in $(36)$ : we could hence expect realization of both features via shifting since ${ }^{*} \alpha \mathrm{A} \alpha \mathrm{A}$ does not block association of either feature. There is, however, a blocking effect that arises from the tonal specification of the second TBU: It is specified as [-U], exactly as the initial TBU. It is hence impossible for the initial register feature $[-\mathrm{U}]$ to shift to this TBU due to ${ }^{*} \alpha \mathrm{A} \alpha \mathrm{A}$ (39d). Henceforth, we are in a situation where only one of the two floating tones can be realized: either the floating $[+\mathrm{r}](39 \mathrm{~b})$ or the floating $[+\mathrm{U},+\mathrm{r}](39 \mathrm{c})$. Since $+\mathrm{U}>\mu$ is ranked above $+\mathrm{r}>\mathrm{U}$, the choice is made in favor of the latter and candidate (39c) emerges as the winner.

The only remaining mystery given this analysis are the contexts 2.1 and 2.2. We expect 1.1 in both cases that results if the $[+\mathrm{r}]$ overwrites the initial $[-r]$ feature (40). In contrast, no surface effect can be observed for these bases.

It is argued that this special behaviour follows from an OCP constraint against derived 1.1 sequences (41). It is not violated by two high tones that already were adjacent in the underlying structure but only if this marked sequence is created by some epenthetic association. It is clear that this constraint type is rather complex and would be an illicit constraint type in correspondence theory since it is neither a faithfulness nor 
(39) 4.3 - Indirect blocking and preference for $[+\mathrm{U},+\mathrm{r}]$

\begin{tabular}{|c|c|c|c|c|}
\hline & 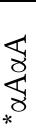 & $\stackrel{\vec{\lambda}}{\hat{\Lambda}}_{+}$ & $\stackrel{\stackrel{\wedge}{\wedge}}{\stackrel{\leftrightarrow}{+}}$ & 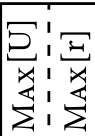 \\
\hline 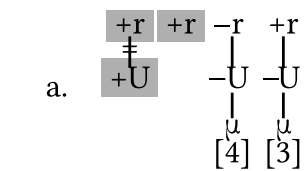 & & *! & * & $\begin{array}{c}1 \\
\vdots \\
\vdots \\
1 \\
1\end{array}$ \\
\hline 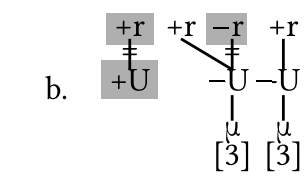 & & *! & & $\begin{array}{r}1 \\
\vdots \\
* \\
1 \\
1 \\
1\end{array}$ \\
\hline 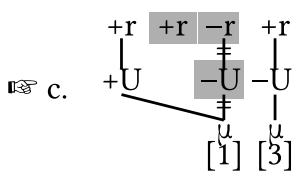 & & & * & $\begin{aligned} 1 \\
1 \\
1 \\
1 \\
1 \\
1 \\
1\end{aligned}$ \\
\hline 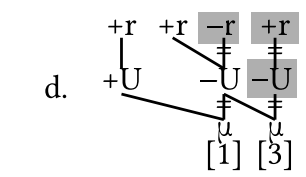 & *! & & & $\begin{array}{c}1 \\
* \\
1 \\
1\end{array}$ \\
\hline
\end{tabular}

(40) Exceptional blocking for 2.1 and 2.2

a.

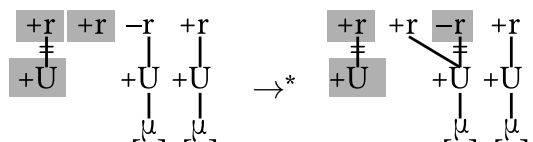

[2] [1]

[1] [1]

b.

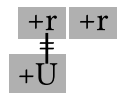<smiles>[Te][Te]1=NC=N1</smiles>

[2] [2]

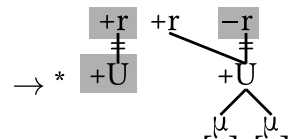

[1] [1]

a markedness constraint. In coloured containment theory, such a reference to the underlying status of elements or associations is easily possible. Note that the constraint formulation in (41) does not conform to the cloning hypothesis since it does not refer exclusively to phonetically visible or all structure. This apparent weakening of the constraint system, on the other hand, can predict grandfather effects that are notoriously challenging for standard parallel OT (McCarthy 2002; 2003; Mascaró 2003; Lubowicz 2003). 
(41) $\mathrm{OCP}_{\mathrm{DER}}$ : Assign $*$ to every sequence of adjacent tones 1 if one of the associations between TBU and $[+\mathrm{U}]$ or $[+\mathrm{U}]$ and $[+\mathrm{r}]$ is epenthetic.

The effect of undominated OCP $\mathrm{DER}_{\text {is }}$ briefly shown in (42). Since the derived 1.1-sequence ( $42 \mathrm{~b})$ is excluded, the candidate that does not realize any of the floating features wins the competition.

(42) 2.1 - No change since derived 1.1 impossible

\begin{tabular}{|c|c|c|c|c|c|}
\hline & $\overbrace{0}^{\frac{n}{m}}$ & $\begin{array}{l}1 \\
1 \\
1 \\
1 \\
1\end{array}$ & \begin{tabular}{l}
\multicolumn{2}{c}{} \\
$\hat{\Lambda}$ \\
$\stackrel{P}{+}$
\end{tabular} & 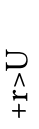 & 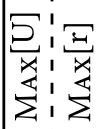 \\
\hline 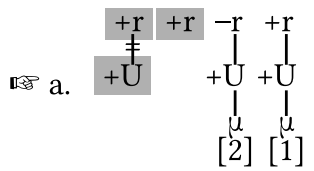 & & $\begin{array}{l}1 \\
1 \\
1 \\
1 \\
1 \\
1 \\
1\end{array}$ & * & * & $\begin{array}{l}1 \\
1_{1} \\
1 \\
1 \\
1\end{array}$ \\
\hline 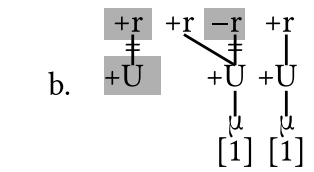 & *! & $\begin{array}{l}1 \\
1 \\
1 \\
1 \\
1 \\
1 \\
1\end{array}$ & * & & $\begin{array}{c}1 \\
1^{*} \\
1 \\
1 \\
1\end{array}$ \\
\hline 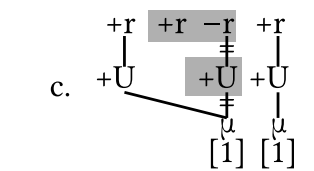 & *! & in & & * & $\begin{array}{l}1 \\
\vdots \\
1 \\
1 \\
1\end{array}$ \\
\hline
\end{tabular}

The analysis for the raising morphemes based on two floating tonal structures $[+\mathrm{r}]$ and $[+\mathrm{U},+\mathrm{r}]$ is summarized in $(43)$.

(43) Changes of raising morphemes ${ }^{\mathrm{c}}$

\begin{tabular}{|c|c|c|c|c|}
\hline & 1 & 2 & 3 & 4 \\
\hline & \multicolumn{4}{|c|}{ No association (38) } \\
\hline 2 & & iation (42) & 7 & Only $[+\mathrm{r}](37)$ \\
\hline 4 & & and $[+\mathrm{r}](36)$ & Only $[+\mathrm{U},+\mathrm{r}](39)$ & 7 \\
\hline
\end{tabular}




\section{Different high tones in Macuiltianguis Zapotec}

\subsection{Data}

The Otomanguean language Macuiltianguis Zapotec (= MacZ, Broadwell \& Zhang 1999; Broadwell 2000; Broadwell et al. 2011; Foreman 2006; Tejada $2012)^{13}$ has three level tones and downstepped high tones $\left(=\mathrm{a}^{! 1}\right){ }^{14}$ The only existing tone sequences on vowels are 31 and 13 and can only surface on long vowels. This distribution follows straightforwardly from assuming that the TBU in MacZ is the $\mu$ and no true contour tones are possible in the language.

The prefix $/ \mathrm{gu}^{1}-/$ marking potential aspect causes an additional high tone on the directly adjacent TBU, irrespective of whether this TBU belongs to another prefix (44a) or the initial TBU of a verb stem (44b-d). This high tone crucially only overwrites the tone of a following $\mu$ and a tonal contour for underlyingly low-toned long vowels result $(44 \mathrm{~b}, \mathrm{c})$. In addition, a downstep surfaces if an original low tone is overwritten by the high tone and another high tone follows (44d). This follows straightforwardly in an autosegmental account where the underlying low tone is only deassociated but still part of the underlying representation: an unassociated low tone between two high tones is one standard representation for downstep (Pulleyblank 1986; Odden 1988).

(44) Floating high tone in the potential (Broadwell et al. 2011, 4, 8)

\begin{tabular}{|c|c|c|}
\hline UNDERLYING & SURFACE & \\
\hline a. $g u^{1}-d i^{2}-b i^{3} \theta: a^{3}-n a^{3}-n a^{3}$ & $g u^{1}-d i^{1}-b i^{3} \theta: a^{3}-n a^{3}-n a^{3}$ & 'S/he will wet it' \\
\hline b. gu $^{1}-$ si: $^{3}$ ga $^{1}$ 1-na ${ }^{3}-a^{3}$ & $\mathrm{gu}^{1}-\mathrm{si}^{13} \mathrm{ga}^{1}{ }^{1}-\mathrm{na}^{3}-\mathrm{na}^{3}$ & 'S/he will push it' \\
\hline c. $g u^{1}-$ tu: $^{3} \mathrm{bi}^{1}-n a^{3}-n a^{3}$ & gu ${ }^{1}-$ tu: $^{13} \mathrm{bi}^{1}-\mathrm{na}^{3}-$ na ${ }^{3}$ & 'I will roll it' \\
\hline d. $g u^{1}-1 a^{3}$ p:a $^{1}-n a^{3}-n a^{3}$ & 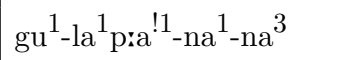 & 'S/he will clean it up' \\
\hline
\end{tabular}

13 The descriptions differ slightly in the empirical facts about the morphological high tones. The data and generalizations about morphological high tones in the following are all taken from Broadwell et al. (2011). One difference between the descriptions is the existence of contrastive stress in Broadwell \& Zhang (1999), Broadwell (2000), Foreman (2006), and Tejada (2012) but not in Broadwell et al. (2011). Foreman (2006) explicitly states that the phonetic realization of stress is difficult to determine.

${ }^{14}$ For reasons of consistency with section 3 , I notate the tones with the numbers high ${ }^{1}$, mid $^{2}$, and low ${ }^{3}$; contra to the notation in the sources. 
Although MacZ employs phonological tone spreading, this additional high tone must be analyzed as an idiosyncratic property of this morpheme and not as a result of the general tonal phonology of the language. As can be seen in (45), the phonologically predictable tone spreading in MacZ is found for suffixes preceding a stem ending in a high or mid tone. The suffixtone becomes mid (45a) and high (45b) respectively in those contexts. As can be seen in (45c), this spreading is blocked by $/ 1 /$.

(45) Final high and mid tones spread (Broadwell et al. 2011, 3)

\begin{tabular}{|c|c|c|}
\hline UNDERLYING & SuRface & \\
\hline a. $\quad$ be $^{2}-1 a^{3}: \mathrm{lja}^{2}-\mathrm{na}^{3}-\mathrm{na}^{3}$ & $\mathrm{be}^{2}-1 a^{3}$ :lja ${ }^{2}-n a^{2}-\mathrm{na}^{3}$ & 'S/he spilled it' \\
\hline b. $\quad$ be ${ }^{2}-a^{3}{ }^{3}: a^{1}-n a^{3}-n a^{3}$ & be ${ }^{2}-\mathrm{la}^{3} \mathrm{p} \mathrm{a}^{1}-$ na ${ }^{1}-$ na ${ }^{3}$ & 'S/he cleaned it up' \\
\hline c. $\quad \mathrm{be}^{2}-\mathrm{si}^{3} \mathrm{ga}^{1} \mathrm{p}-\mathrm{na}{ }^{3}-\mathrm{na}{ }^{3}$ & $\mathrm{be}^{2}-$ si: $^{3} \mathrm{ga}^{1} 1-n a^{3}-$ na ${ }^{3}$ & 'S/he pushed it' \\
\hline
\end{tabular}

Crucially, mid toned prefixes do not cause tone spreading to a following TBU. This can also be observed in (45) since all verbs are preceded by the mid toned prefix $/ \mathrm{be}^{2}-/$. It is hence not easily possible to argue that the tonal changes in (44) are due to simple phonological tone-spreading process since this would be expected for the prefix-tones in (45) as well.

A second context for additional high tones in MacZ is the 1SG (46) where an additional high tone is realized in different positions in its base. The choice between these different landing sites of the additional high tone is phonologically predictable: it surfaces on a vowel followed by $/ 2 /$ (46a), on the leftmost low toned TBU if there is no such vowel (46b), and on the rightmost mid toned TBU if there is no low toned TBU (46c). ${ }^{15}$ If the additional $\mathrm{H}$ is realized on an underlyingly long low toned vowel, a long high toned vowel followed by a downstep results (cf. 'I rolled it' in (46b)). ${ }^{16}$

${ }^{15}$ This is one area where the descriptions differ in their generalizations: some argue that the high tone docks to the stressed vowel. Whatever the motivation for the non-local $\mathrm{H}$-realization, the asymmetries discussed in this paper remain.

${ }^{16}$ In Tejada (2012), only two examples for the realization of the 1SG high tone are given and the one where it is realized on a long vowel in fact shows a contour tone (/be ${ }^{3}$ da: $:^{3} a^{2}=\mathrm{ya}^{1} \mathrm{P} /->\left[\mathrm{be}^{3}-\mathrm{da:}^{31} \mathrm{ga}^{2}=\mathrm{ya}^{1}\right.$ ?] 'I ran into him' (Tejada 2012, 268)), contra the generalization in Broadwell et al. (2011). Cf. footnote 13 on other inconsistencies in the descriptions. 
(46) 1.Singular (Broadwell et al. 2011, 6, 7)

\begin{tabular}{|c|c|c|c|}
\hline & UNDERLYING & \multicolumn{2}{|l|}{ SURFACE } \\
\hline & $\mathrm{be}^{2}-\mathrm{si}^{3} \mathrm{ga}^{1}$ P-ja ${ }^{3}-\mathrm{na}^{3}$ & $\mathrm{be}^{2}-$ si $^{3} \mathrm{ga}^{1}$ 1-ja ${ }^{3}-\mathrm{na}^{3}$ & 'I pushed it' \\
\hline & $b e^{2}-\int u^{2} P n i^{1}-j a^{3}-n a^{3}$ & $b e^{2}-\int u^{1} 2 n i^{1}-j a^{1}-n a^{3}$ & 'I wrinkled it' \\
\hline b. & $b e^{2}-d^{2} t: u^{3}-j a^{3}-n a^{3}$ & $b e^{2}-$ de $^{2} t \mathrm{~g}: \mathrm{u}^{1}-\mathrm{ja}^{1}-\mathrm{na}^{3}$ & 'I folded it' \\
\hline & $b e^{2}-d i^{2}-g a a^{3} \mathrm{si}^{2}-j a^{3}-n a^{3}$ & $b e^{2}-d i^{2}-g a i^{1} s i^{2}-j a^{2}-n a^{3}$ & 'I scared it' \\
\hline & $b e^{2}-$ tu: $^{3} \mathrm{bi}^{1}-\mathrm{ja}{ }^{3}-n a^{3}$ & $b e^{2}-{ }^{2}:^{1 !} b i^{1}-j a^{1}-n a^{3}$ & 'I rolled it' \\
\hline c. & $b e^{2}-\int a^{2} t: a^{2}-j a^{3}-n a^{3}$ & $b e^{2}-\int a^{2} t: a^{1}-j a^{1}-n a^{3}$ & 'I ironed it' \\
\hline & $b e^{2}-n e^{2}{ } \mathrm{si}^{2}-\mathrm{ja}^{3}-n a^{3}$ & $b e^{2}-n e^{2}$ si $^{1}-\mathrm{ja}^{1}-n a^{3}$ & 'I submerged it' \\
\hline
\end{tabular}

The two floating high tones in MacZ hence show an interestingly different behaviour with respect to locality: Whereas the high tone in the potential is only realized locally on the stem-initial TBU and creates contour tones on long vowels, the high tone in the $1 \mathrm{SG}$ can be realized on non-adjacent TBU's and overwrites both tones of a long vowel. These asymmetries are summarized in (47).

(47) Two different floating high tones

\begin{tabular}{|c|c|c|}
\hline RoOT & $1 \mathrm{SG}$ & Potential \\
\hline $\mathrm{tu}^{3}: \mathrm{bi}^{1}$ & tu: ${ }^{1 !} \mathrm{bi}^{1}$ & $\mathrm{tu}^{31} \mathrm{bi}^{1}$ \\
\hline $\mathrm{si}^{3}{ }_{\mathrm{ga}}{ }^{1}$ ? & $\mathrm{si}^{3}{ }^{3} \mathrm{ga}^{1}$ ? & $\mathrm{si}^{31} \mathrm{ga}^{1}$ ? \\
\hline
\end{tabular}

Under the assumption of tonal primitives, these asymmetries are mysterious. Why can one H only associate locally and only to a single TBU (48a) whereas the other searches non-locally for a preferred docking site and overwrites the tone on both $\mu$ 's of a long vowel (48b)? In Broadwell et al. (2011), the (non-local) placement of the H-tone in the 1SG is taken as an argument for process-based morphology. In contrast, I present an autosegmental account for the floating tones in MacZ based on the assumption of sub-tonal features.

(48) Two types of morphological tones

a. Pot

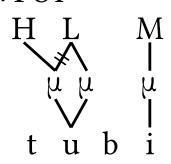

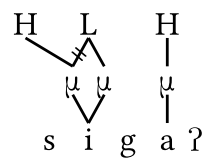

b. $1 \mathrm{SG}_{\mathrm{G}}$

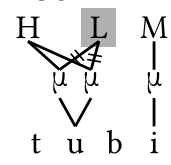

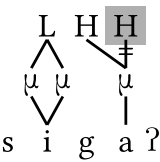




\subsection{Tone feature analysis}

The asymmetric behaviour of floating high tones in MacZ is predicted in a purely phonological account based on sub-tonal features. The specifications for the three tones of MacZ is repeated in (49) from (5). Recall that underspecified tones are again possible that are interpreted with a phonetic default feature $[-r]$. The featural representation of the two types of floating high tones in MacZ is given in (50): The 1SG contains a prefixed $[+\mathrm{r}]$ feature whereas the potential prefix is followed by a floating fully specified high tone $[+\mathrm{U},+\mathrm{r}]$. As in the discussion of MIB, the segmental portions of the relevant morphemes are ignored in the following and only the floating tonal structure is given in all tableaux. ${ }^{17}$

(49) Tones in MacZ

\begin{tabular}{|c|c|c|c|c|}
\hline $\mathbf{3}$ & $\mathbf{2}$ & $\mathbf{1}$ & $\mathbf{3}$ & $\mathbf{2}$ \\
\hline \hline $\begin{array}{r}-\mathrm{r} \\
\mid\end{array}$ & $\begin{array}{r}-\mathrm{r} \\
\mid\end{array}$ & $\begin{array}{r}+\mathrm{r} \\
+\mathrm{U}\end{array}$ & & \\
$+\mathrm{U}$ & $+\mathrm{U}$ & $-\mathrm{U}$ & $+\mathrm{U}$ \\
\hline
\end{tabular}

(50) Two floating tones

\begin{tabular}{|c|c|}
\hline a. POT & b. 1SG \\
\hline$+\mathrm{r}$ & $+\mathrm{r}$ \\
$+\mathrm{U}$ & \\
\hline
\end{tabular}

The basic tonal overwriting of these floating tones is absolutely parallel to the analysis for MIB in section 3: the parsing constraints $+\mathrm{U}>\mu$ and $+\mathrm{r}>\mathrm{U}$ demand association of the floating tonal features to a host and $* \mathrm{U}_{\mu} \mathrm{U}$ and ${ }^{* \mathrm{R}} \mathrm{U}^{\mathrm{R}}$ demand overwriting of the underlying tone specification since there are no contour tones. In the following subsections, it is shown how the simple representational difference between an underspecified floating high tone (50b) and a fully specified floating high tone (50a) predicts the two positional asymmetries we observed for floating high tones in MacZ.

\subsubsection{The locality asymmetry}

Recall that the empirical generalization about realizing the $1 \mathrm{SG}$ in a nonlocal position was the preference for being realized adjacent to a $/ \mathrm{P} /$, for overwriting low tones instead of mid tones, and for overwriting the rightmost mid tone if no low tone is present (cf. the data in (46)). The first preference is taken to be a standard case of consonant-tone interaction

17 The 1SG morpheme is interesting independently since it is taken to be a circumfix consisting of a prefixed tonal portion and a suffixed segmental portion. 
(Lee 2008; Tang 2008), ${ }^{18}$ triggered by the markedness constraint (51a). ${ }^{19}$ The other two preferences fall out as epiphenomena from the ranking of constraints ensuring the realization of the different tones and a constraint favoring mid tones on the initial TBU of a stem. For reasons of space, these additional contexts are not discussed. They do not add anything interesting to the major point here that is the asymmetry between the two morphological high tones.

As was shown in (13), non-local realization of a tone (for a prefix tone: on a non-initial TBU) in the present containment-based system implies non-realization of the 'crossed' tonal features. This does not only violate ${ }^{*}$ Cross but also the constraints $(51 \mathrm{a}, \mathrm{b})$ demanding full phonetically visible specification for tonal features. As we will see below, the need to reach a preferred landing site for a high tone will result in structures that are underspecified for $[ \pm \mathrm{r}]$ but never in structures that are underspecified for $[ \pm \mathrm{U}]$. The smaller feature structure is hence more mobile whereas non-local association of the bigger feature structure would result in too many 'destruction' of feature structure on its way.

(51) a. ${ }_{-}{ }_{-} \mathrm{G} / \mathrm{H}:$ Assign ${ }^{*}$ for every phonetically visible vowel that is associated to $[+\mathrm{r}]$ but not followed by a $[+\mathrm{cg}]-$-sound.

b. HAVE[U]: Assign * for every phonetically visible $\mu$ that is not associated to a $[ \pm \mathrm{U}]$ in a phonetically visible way.

c. HAVE[r]: Assign * for every phonetically visible $[ \pm \mathrm{U}]$ that is not associated to a $\overline{[ \pm r}]$ in a phonetically visible way.

Tableaux (52) and (53) show how the locality asymmetry for morphological high tones in MacZ falls out from their different underlying representation and a ranking of these standard constraints about unmarked autosegmental structures. The base in (52) and (53) ends in a / $/$, (51a) hence prefers non-local realization of the two high tones on the second TBU: Local assimilation in candidates (52a) and (53a) violate ${ }^{*}{ }_{-} \mathrm{CG} / \mathrm{H}$. Non-local realiza-

${ }^{18} \mathrm{Cf}$. also the blocking of high and mid spread across $/ \mathrm{P} /$ (see (45)).

19 There are various proposals that tones and laryngeal features should be combined (e.g., Halle \& Stevens 1971; Bao 1990; Duanmu 1990) with, for example, a feature [stiff/slack vocal folds] that can occur on both vowels and consonants and is interpreted as voicing/voicelessness or L/H-tone respectively. Those tonal features are orthogonal to the sub-tonal features argued for in this paper. It is an interesting question for future research whether and how those different tonal feature systems can and should be combined. Since determining the concrete landing site of the floating tones is not the main aim of this paper (especially given the different empirical generalizations in the sources; cf. footnote 15), I stick to this rather descriptive constraint (51a). 
tion in (52b) and (53b) satisfies this constraint but results in a violation of *CROss and additional violations of HAVE[r] for (52b) and of HAVE[U] for (53b): the 'crossed' features must be phonetically invisible. ${ }^{*}$ CROss is relatively low-ranked and has no effect, HAVE[U], on the other hand, is pretty high-ranked and crucially above ${ }^{*}{ }_{-\mathrm{CG}} / \mathrm{H}$. For the 'bigger' tone structure of the potential high tone (53), association to this preferred landing site is hence excluded since it necessarily implies that the crossed initial TBU of the stem remains without a $[ \pm \mathrm{U}]$ specification. ${ }^{20}$ Note that the 'mid' tone in (52a) is not a licit tone combination in MacZ; a point that is taken up below.

(52) 1Sg: Non-local association

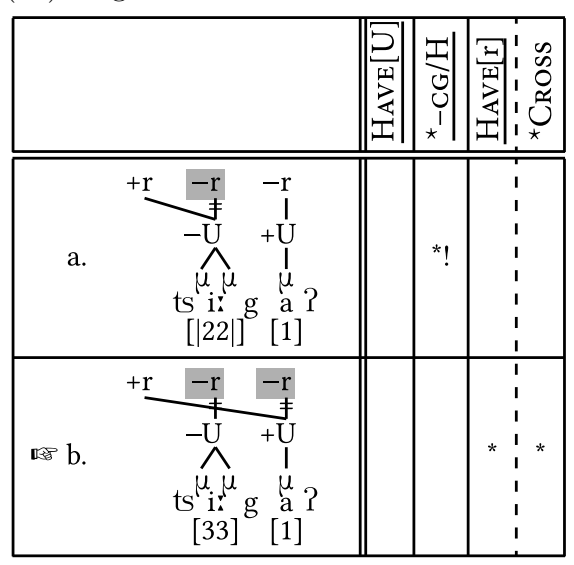

(53) Potential: Only local association

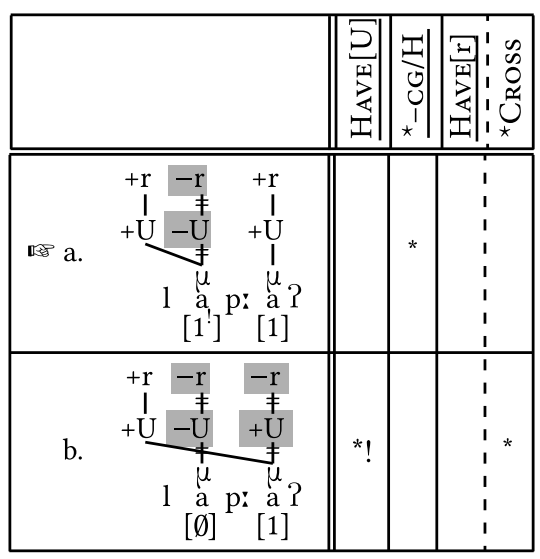

\subsubsection{The long-vowel asymmetry}

Before we turn to the predictions of high tone realization in the context of a long vowel, an additional note regarding the overwriting of the high tone in the $1 \mathrm{SG}$ is necessary. If the floating $[+\mathrm{r}]$ feature is expected to be realized on an underlyingly low toned TBU, some additional repair is necessary simply because $[-\mathrm{U},+\mathrm{r}]$ is not a licit tonal feature structure in MacZ. A $[+\mathrm{r}]$ feature can only be realized on a $[+\mathrm{U}]$ register feature and epenthesis of such a feature hence becomes necessary to associate a floating

${ }^{20}$ Given that all other repair strategies to supply the $\mu$ with a $[ \pm \mathrm{U}]$ are excluded: spreading of the high tone to all stem-TBU's implies too many violations of DEPAL (55b) and epenthesis of $[ \pm \mathrm{U}]$ would also imply epenthesis or spreading of a $[ \pm \mathrm{r}]$ to provide this otherwise missing feature: both options are excluded by higher-ranked constraints. 
$[+\mathrm{r}]$. This repair is sketched in (54). This additional epenthesis will become crucial in the following tableaux.

(54) $[+\mathrm{r}]$ realized on an underlying low toned TBU

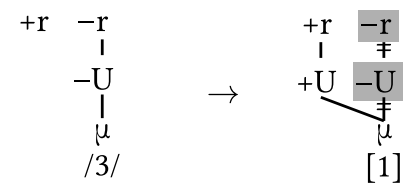

Two additional constraints that are relevant in the context of an initial long vowel are given in (55): for one, contour tones as combination of two different tones on a single vowel are marked (55a) and second, the insertion of an epenthetic association line between two underlying elements is preferably avoided $(55 \mathrm{~b})$. Note that $* \mathrm{~T}^{\mathrm{T}} \mathrm{V}^{\mathrm{T}}$ is sensitive to yet another tier than the anti-contour constraints $\left.* \mathrm{U}_{\mu}^{\mathrm{U}} \overline{(\text { see }}(9 \mathrm{~b})\right)$ and ${ }^{* \mathrm{r}} \mathrm{U}^{\mathrm{r}}$ discussed above since it refers to vowels and their tones.

(55) a. ${ }^{*} \mathrm{~T}_{\mathrm{V}} \mathrm{T}$ : Assign $*$ for every $\mathrm{V}$ that is phonetically visibly linked to two tones.

b. DePAL: Assign * for every colourless association line between a morphologically coloured $[ \pm \mathrm{U}]$ and a morphologically coloured $\mu$.

How the ranking of these constraints predict the asymmetric behaviour of the two morphological high tones with respect to long vowels is shown in tableaux (56) and (57). Association of the fully specified floating high tone of the 1SG results in a contour tone in (56a) since higher-ranked DEPAL prohibits further associations to a $\mu$ as in $(56 \mathrm{~b})$. Crucially, the one violation of DEPAL in winning candidate (56a) is unavoidable since higher-ranked $+\mathrm{U}>\mu$ demands that the floating tone must associate to some $\mu$. For the floating underspecified potential high tone, the predictions are interestingly different. This difference is mainly due to the fact that this $[+\mathrm{r}]$ feature does not directly associate to an underlying feature of the stem but to an epenthetic $[+\mathrm{U}]$ feature (cf. the discussion of (54)). Since DePAL is only specified for morphologically coloured elements, it is not violated if an association line is added to an element that were not present underlyingly (cf. Trommer \& Zimmermann 2014 for a discussion of this conception of DePAL). The violation of ${ }^{\mathrm{T}} \mathrm{V}^{\mathrm{T}}$ in candidate (57a) can hence be avoided in the winning candidate $(5 \overline{7 b})$. 
(56) 1Sg-high tone: contour tone

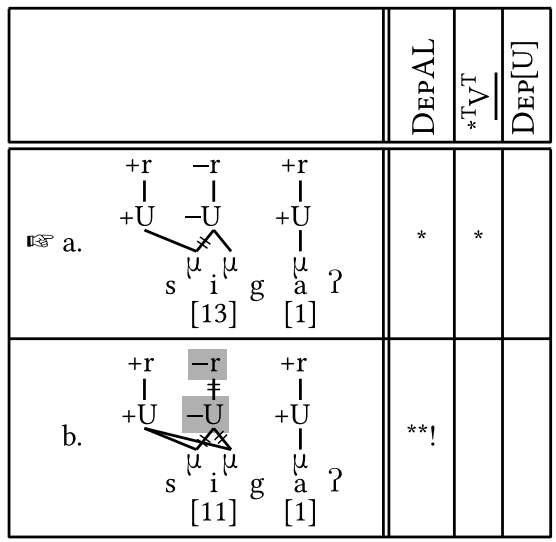

(57) Potential high tone: overwriting

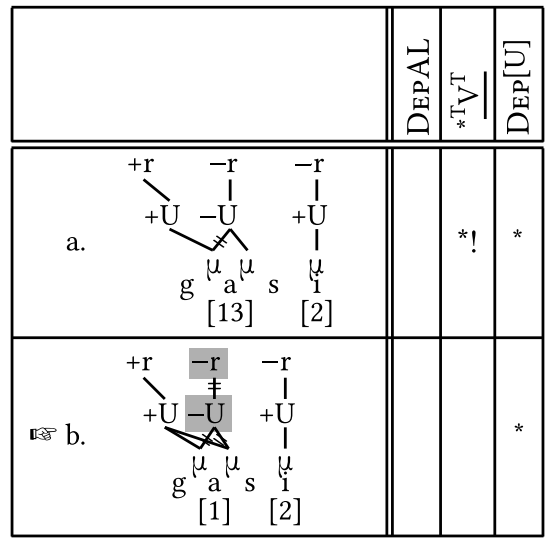

These tableaux optimize a base that starts with low toned long vowels. The analysis of the long overwriting in (57) apparently implies that a contour is expected for long mid toned vowels since the $[+\mathrm{r}]$ would directly associate to an underlying $[+\mathrm{U}]$ feature under violation of DEPAL. However, this outcome is excluded by independent phonological constraints: 13 and 31 are the only possible tone sequence on long vowels in MacZ.

\section{Conclusion}

This paper presented two case studies of exceptional tonal behaviour in two Otomanguean languages that challenge the standard autosegmental account of floating tones based on tonal primitives. It was shown that the type allomorphy of different tonal changes in MIB and the locality asymmetry observed for different morphological high tones in MacZ follows in a purely phonological acount if sub-tonal features are adopted. Crucially, standard constraint about autosegmental associations then predict all the effects we observe for the different floating tones: That lowering morphemes in MIB show a stepwise lowering for some bases and no effect for others follows from two different floating low tone features that are in complementary distribution and can only associate to the base if their specification is 'new' and not already underlyingly present. And that two different morphological high tones in MacZ have different properties with respect to where they are realized and whether they form contour tones on long vowels or not is a simple consequence from different underlying high tones: a fully specified one that must associate locally and an under- 
specified one that can reach a preferred landing site since it's non-local association does not imply too much destruction on its way.

These analyses hence strengthen the argument for sub-tonal features and for (abstract) underlying representations as the source for apparently exceptional or idiosyncratic behaviour.

\section{References}

Alexander, Ruth María. 1980. Gramática Mixteca de Atatlàhuca. Verano: Instituto Lingüístico de Verano.

Alexander, Ruth María and Cornelia Mak. 2009. El mixteco: idioma de una cultura antigua. Verano: Instituto Lingüístico de Verano.

Bao, Zhiming. 1990. On the nature of tone. Doctoral dissertation. MIT.

Bao, Zhiming. 1999. The structure of tone. Oxford: Oxford University Press.

Bermúdez-Otero, Ricardo. in preparation. Stratal Optimality Theory. Oxford: Oxford University Press.

Blaho, Sylvia, Patrick Bye and Martin Krämer (eds.). 2007. Freedom of analysis? Berlin \& New York: Mouton de Gruyter.

Broadwell, George Aaron, 2000. Macuiltionguis Zapotec tone paradigms. Unpublished manuscript, SUNY, Buffalo.

Broadwell, George Aaron, John Foreman and Lee Bickmore, 2011. Floating H tones and the tonology of Macuiltianguis Zapotec. SSILA 2008.

Broadwell, George Aaron and Jie Zhang, 1999. Tonal alignment constraints and the nature of evaluation. Paper presented at the 73rd Annual Meeting of Linguistic Society of America, Los Angeles.

Burzio, Luigi. 2011. Derived environment effects. In M. van Oostendorp, C. Ewen, E. Hume and K. Rice (eds.) The Blackwell companion to phonology. Malden, MA \& Oxford: Wiley-Blackwell. 2089-2114.

Chao, Yuan Ren. 1930. A system of tone-letters. Le maitre phonetique 45. 24-27.

Duanmu, San. 1990. A formal study of syllable, tone, stress and domain in Chinese languages. Doctoral dissertation. MIT.

Dürr, Michael. 1987. A preliminary reconstruction of the Proto-Mixtec tonal system. Indiana 11. 19-61.

Foreman, John Olen. 2006. The morphosyntax of subjects in Macuiltianguis Zapotec. Doctoral dissertation. UCLA.

Goldrick, Matthew 2000. Turbid output representations and the unity of opacity. In M. Hirotani, A. Coetzee, N. Hall and J.-Y. Kim (eds.) Proceedings of NELS 30. Amherst: University of Massachusetts. 231-245.

Goldsmith, John. 1976. Autosegmental phonology. Doctoral dissertation. MIT.

Halle, Morris and Kenneth N. Stevens. 1971. A note on laryngeal features. Quarterly Progress Report, Research Laboratory of Electronics 101. 198-213.

Hollenbach, Barbara. 2003. The historical source of an irregular Mixtec tone-sandhi pattern. In M. R. Wise, T. Headland and R. Brend (eds.) Language and life: Essays in memory of Kenneth L. Pike. Dallas, TX: SIL International. 535-552. 
Hyman, Larry M. 1992. Register tones and tonal geometry. In H. van der Hulst and K. Snider (eds.) The phonology of tone: The representation of tonal register. Berlin \& New York: Mouton de Gruyter. 75-108.

Hyman, Larry M. 2013. Morphological tonal assignments in conflict: Who wins? In UC Berkeley Phonology Lab Annual Report. Berkeley, CA: University of California, Berkeley. 327-343.

Itô, Junko. 1988. Syllable theory in prosodic phonology. New York: Garland.

Lee, Seunghun. 2008. Consonant-tone interaction in Optimality Theory. Doctoral dissertation. Rutgers University.

Lubowicz, Ania. 2003. Local conjunction and comparative markedness. Theoretical Linguistics 29. 101-112.

Lubowicz, Anna. 2002. Derived environment effects in Optimality Theory. Lingua 112. $243-280$

Mak, Cornelia. 1953. A comparison of two Mixtec tonemic systems. International Journal of American Linguistics 19. 85-100.

Mascaró, Joan. 2003. Comparative markedness and derived environments. Theoretical Linguistics 29. 113-22.

McCarthy, John J. 1979. Formal problems in Semitic phonology and morphology. Doctoral dissertation. MIT.

McCarthy, John J. 2002. Comparative markedness. In A. Carpenter, A. Coetzee and P. de Lacy (eds.) Papers in Optimality Theory II. Amherst: GLSA. 171-246.

McCarthy, John J. 2003. What does Comparative Markedness explain, what should it explain, and how? Theoretical Linguistics 29. 141-155.

McKendry, Inga. 2013. Tonal association, prominence and prosodic structure in SouthEastern Nochixtlán Mixtec. Doctoral dissertation. University of Edinburgh.

McPherson, Laura. 2017. Multiple feature affixation in Seenku plural formation. Morphology 27. 217-252.

Odden, David. 1988. Floating tones and contour tones in Kenyang. Studies in African Linguistics 19. 1-34.

Odden, David. 1995. Tone: African languages. In J. A. Goldsmith (ed.) The handbook of phonological theory. Cambridge, MA \& Oxford: Blackwell. 444-475.

Oostendorp, Marc van, 2006. A theory of morphosyntactic colours. Unpublished manuscript, Meertens Institute, Amsterdam (https://tinyurl.com/y8jkvnx2).

Oostendorp, Marc van. 2007. Derived environment effects and consistency of exponence. In Blaho et al. (2007, 123-148).

Oostendorp, Marc van. 2008. Incomplete devoicing in formal phonology. Lingua 118. 1362-1374.

Oostendorp, Marc van. 2012. Stress as a proclitic in Modern Greek. Lingua 122. 1165-1181.

Picanço, Gessiane Lobato. 2005. Mundurukú: Phonetics, phonology, synchrony, diachrony. Doctoral dissertation. University of British Columbia.

Pike, Kenneth L. 1944. Analysis of a Mixteco text. International Journal of American Linguistics 10. 113-138.

Prince, Alan and Paul Smolensky. 2004. Optimality Theory: Constraint interaction in Generative Grammar. Malden, MA \& Oxford: Blackwell. 
Pulleyblank, Douglas. 1986. Tone in Lexical Phonology. Dordrecht: Reidel.

Revithiadou, Anthi. 2007. Colored turbid accents and containment: A case study from lexical stress. In Blaho et al. (2007, 149-174).

Snider, Keith L. 1990. Tonal upstep in Krachi: Evidence for a register tone. Language 66. 453-474.

Snider, Keith L. 1998. Phonetic realisation of downstep in Bimoba. Phonology 15. 77-101.

Snider, Keith L. 1999. The geometry and features of tone. Dallas, TX: Summer Institute of Linguistics \& University of Texas at Arlington.

Steriade, Donca. 1982. Greek prosodies and the nature of syllabification. Doctoral dissertation. MIT.

Tang, Katrina. 2008. The phonology and phonetics of consonant-tone interaction. Doctoral dissertation. UCLA.

Tejada, Laura. 2012. Tone gestures and constraint interaction in Sierra Juarez Zapotec. Doctoral dissertation. University of Southern California.

Trommer, Jochen, 2011. Phonological aspects of Western Nilotic mutation morphology. Habilitation thesis, University of Leipzig.

Trommer, Jochen. 2015. Moraic affixes and morphological colors in dinka. Linguistic Inquiry 46. $77-112$.

Trommer, Jochen and Eva Zimmermann. 2014. Generalised mora affixation and quantitymanipulating morphology. Phonology 31. 463-510.

Yip, Moira. 1980. The tonal phonology of Chinese. Doctoral dissertation. MIT.

Yip, Moira. 1989. Contour tones. Phonology 6. 149-174.

Zimmermann, Eva. 2017. Morphological length and prosodically defective morphemes. Oxford: Oxford University Press.

Zimmermann, Eva and Jochen Trommer. 2013. The linearization of morphological weight. In F. Heck and A. Assmann (eds.) Rule interaction in grammar. Leipzig: University of Leipzig. 123-161. 